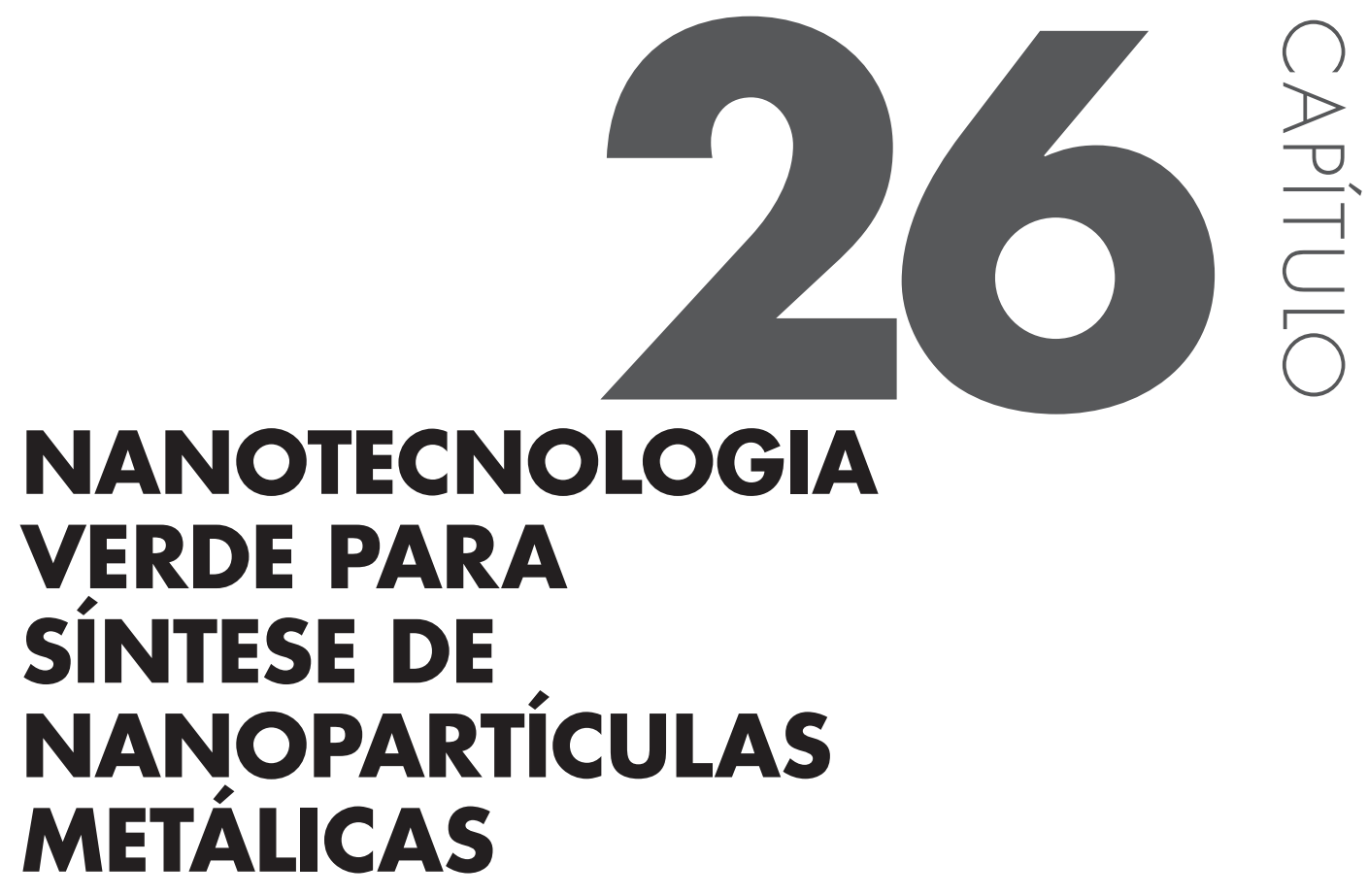

Luciano Paulino Silva

Cínthia Caetano Bonatto

Flávio Duque Estrada Soares Pereira

Luciane Dias Silva

Vanessa Lima Albernaz

Vera Lúcia Perussi Polez

\title{
26.1 INTRODUC̣ÃO
}

A nanobiotecnologia é uma área do conhecimento que integra várias ciências, como a física, a química, a biologia e a ciência dos materiais. As nanopartículas, devido ao seu tamanho em nanoescala (em geral de $1 \mathrm{~nm}$ a $100 \mathrm{~nm}$ ), apresentam propriedades novas ou melhoradas baseadas nas suas características específicas (tamanho, distribuição, morfologia, fase, composição, entre outras) quando comparadas a partículas de maiores dimensões provenientes da mesma fonte na qual as nanopartículas foram formadas.

Nanopartículas metálicas (NPMs) são sistemas nanoestruturados que apresentam características físico-químico-biológicas dependentes da sua composição, tamanho e forma. Dentre as aplicações de NPMs, podem ser 
destacadas a entrega e liberação de drogas (fármacos, hormônios), insumos agropecuários (fertilizantes, vacinas, pesticidas) e cosméticos (essências e cremes); desenvolvimento de superfícies funcionais (embalagens ativas para proteção de alimentos); elaboração de sensores para diagnóstico de doenças, infecções e contaminações (detecção rápida e sensível); desenvolvimento de sistemas de transferência de genes (eficiência aumentada); produção de pontos quânticos (fontes alternativas para imagem por fluorescência); produção de nanopartículas superparamagnéticas (utilizadas, por exemplo, para a biosseparação seletiva e magnetodiálise); controle de pragas/patógenos (efeitos tóxicos); desenvolvimento de catalisadores (eficácia aumentada); desenvolvimento de sistemas de biorremediação (utilizados para remoção de metais pesados); e aplicações na indústria têxtil (na produção de tecidos com propriedades distintas, incluindo a ação antibacteriana $)^{1-7}$.

Utilizam-se duas abordagens para a síntese de nanoestruturados, incluindo NPMs, conhecidas em nanociência e nanotecnologia como "top-down" (de cima para baixo) e "bottom-up" (de baixo para cima). A estratégia top-down consiste na desconstrução de material macroestruturado, geralmente por técnicas de nanolitografia ou por moagem de alta energia, até a obtenção do produto final nanoestruturado. Essa abordagem é comumente utilizada para produção em escala, mas são observadas dificuldades em obter-se uma homogeneidade nas características do produto final. A outra abordagem, bottom-up, segue o caminho oposto, no qual ocorrem interações entre átomos e/ou moléculas individuais para a formação das nanoestruturas. Essa abordagem permite controlar diversos parâmetros, como a distribuição de tamanho e forma das nanopartículas, sendo a mais utilizada na produção de NPMs (Figura 26.1A).

Diversas rotas químicas são utilizadas para a síntese de NPMs a partir de sais metálicos. No entanto, a maioria desses métodos inclui a utilização de solventes tóxicos, a geração de resíduos nocivos para a saúde e o meio ambiente, além de resultar em um consumo de energia alto em rotas geralmente complexas e com múltiplos passos. Nesse sentido, é necessário o desenvolvimento de procedimentos visando à obtenção desses nanossistemas com ampla aplicabilidade tecnológica. Uma abordagem promissora para alcançar esse objetivo é explorar a vasta gama de recursos biológicos disponíveis na natureza por meio da chamada síntese verde ${ }^{8-10}$ (Figura 26.1B).

Síntese verde é a designação comum dada às rotas de síntese que utilizam produtos químicos relativamente atóxicos, biodegradáveis e de custo baixo para sintetizar nanomateriais, tendo como fonte primária ou iniciador da rota um organismo biológico ou partes dele (órgãos, tecidos, células, 
biomoléculas ou metabólitos $)^{11-13}$. Dentre os recursos biológicos disponíveis, os produtos vegetais e animais, algas, fungos, bactérias e a ampla gama de subprodutos derivados de processos agropecuários envolvendo alguns desses organismos possuem potencial para utilização durante a síntese verde de NPMs, por meio de processos de oxirredução em meio aquoso ${ }^{14}$.

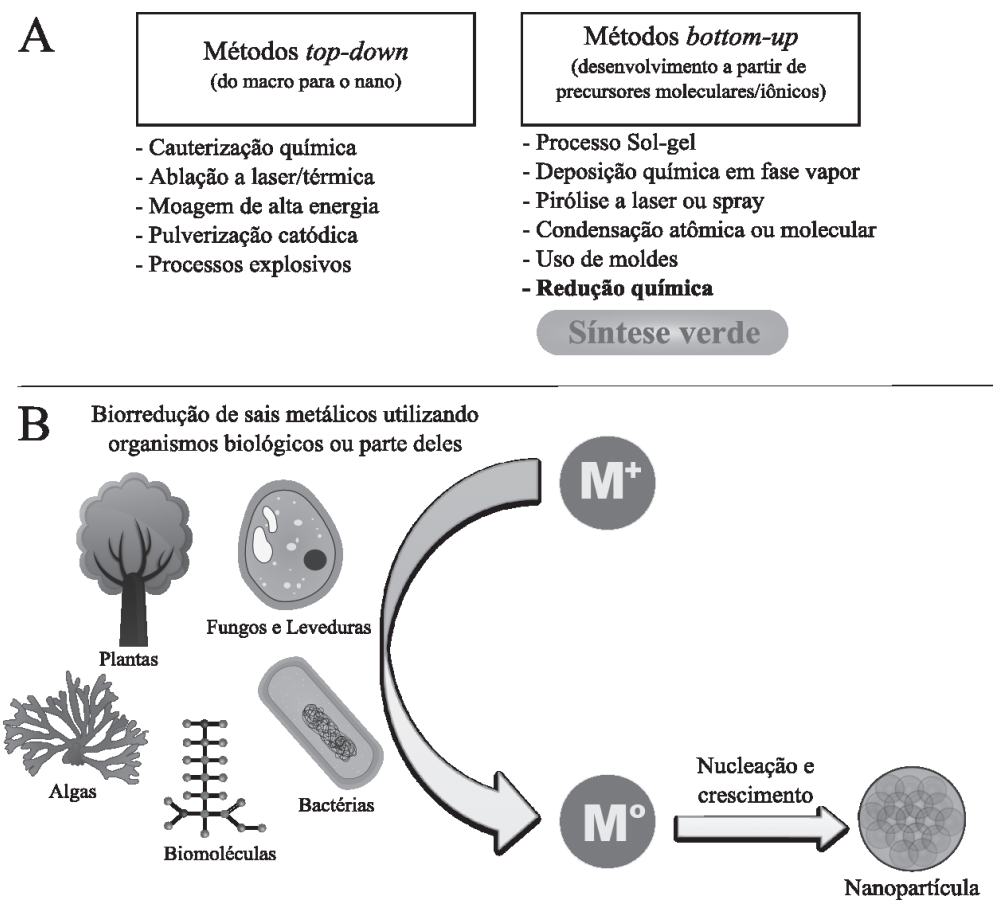

Figura 26.1 Características das principais estratégias utilizadas para produzir nanoestruturas pelas abordagens top-down e bottom-up (A), com destaque para a metodologia de síntese verde de nanopartículas metálicas via redução química de sais metálicos utilizando organismos biológicos como agentes redutores (B).

O aproveitamento da biodiversidade constitui uma etapa importante no conceito de bioeconomia (economia sustentável), no que diz respeito à sustentabilidade das atividades humanas. A nanotecnologia verde é uma abordagem em consonância com a preocupação crescente com questões relacionadas à sustentabilidade utilizando métodos e materiais que visam à geração de produtos com impacto ambiental reduzido associado a ganhos econômi$\cos$ e sociais ${ }^{9,15}$. Esse conceito oferece oportunidades quanto à utilização de biomoléculas ou metabólitos em rotas de síntese verde de NPMs devido ao 
fato de que esses materiais, quando nanoestruturados, apresentam características novas que possibilitam uma vasta gama de aplicações inovadoras, além de conferir, em geral, características almejáveis de biodegradabilidade e a biocompatibilidade.

A síntese verde de NPMs pode ser realizada utilizando organismos procariontes ou eucariontes (incluindo plantas, animais e micro-organismos), ou parte deles, e pode ocorrer no meio intra ou extracelular ${ }^{16}$ (Figura 26.2). Nesse caso, os componentes presentes (biomoléculas e metabólitos secundários) atuam como agentes redutores que promovem a redução do composto-alvo, resultando na formação de $\mathrm{NPMs}^{16}$. Em alguns casos, e de maneira extremamente apropriada quando se almeja a obtenção de uma suspensão coloidal, esses compostos podem também formar uma camada estabilizante (cobertura) na superfície das NPMs, evitando que estas se agreguem ou cresçam desordenadamente durante sua produção. Além disso, a exposição a diferentes fatores (temperatura, $\mathrm{pH}$ e concentração de substrato ou agente redutor) pode alterar a produção de NPMs no meio intra ou extracelular ${ }^{17-20}$. A maioria das NPMs obtidas por meio de rotas de síntese verde apresenta como características almejáveis sob o ponto de vista de sustentabilidade

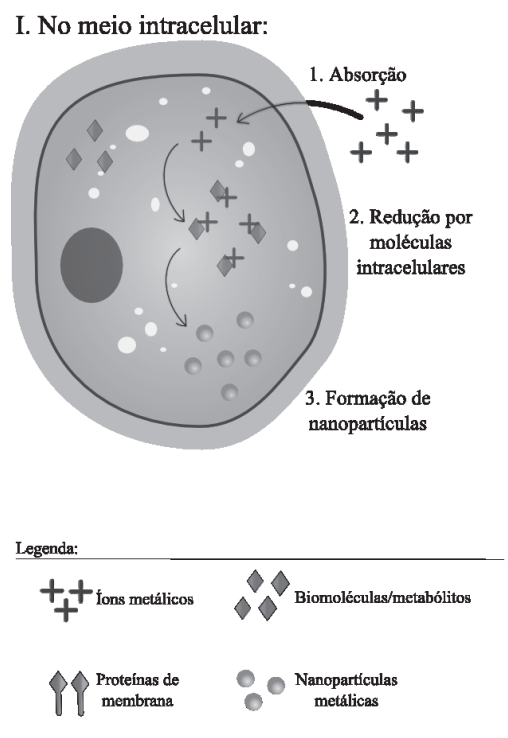

II. No meio extracelular:
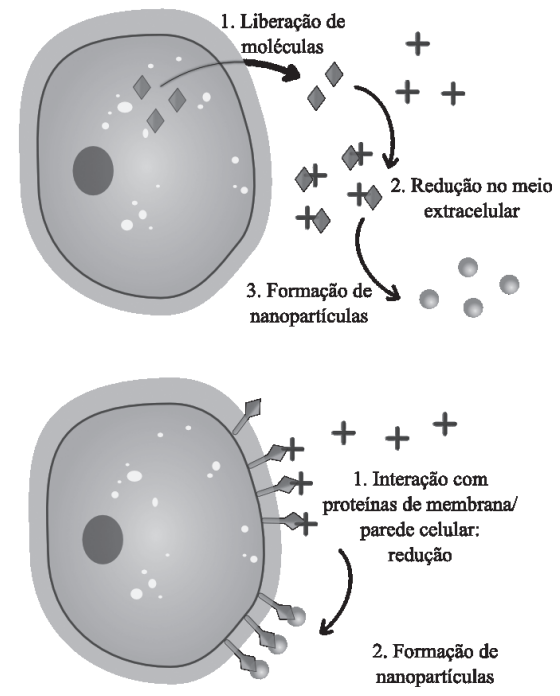

Figura 26.2 Possíveis mecanismos de síntese de nanopartículas metálicas mediada por células. No meio intracelular ocorre absorção dos íons metálicos, que reagem com moléculas intracelulares, onde esses íons são reduzidos e formam nanopartículas. No meio extracelular, a síntese pode ocorrer via interação dos íons metálicos com moléculas liberadas pela célula ou com proteínas de membrana/ parede celular. 
o fato de serem ecoamigáveis (utilizam solventes menos tóxicos), biocompatíveis (podem ser empregadas diretamente a organismos-alvo), simples (número de etapas menor), biodegradáveis (podem ser degradadas por rotas biológicas) e apresentam custo de produção baixo e rendimento alto ${ }^{11,12}$.

Organismos de todos os reinos da vida podem apresentar potencial para utilização em rotas de síntese verde de NPMs. Interessantemente, muitos desses organismos que podem ser utilizados em rotas de síntese verde, além de fazer parte da biodiversidade, são cultivados ou criados. Adicionalmente, componentes provenientes de subprodutos agroindustriais, originalmente sem valor econômico, podem ser utilizados em rotas de síntese verde. De fato, o aproveitamento de subprodutos das cadeias produtivas animal, vegetal e microbiana constitui uma etapa importante a ser avaliada durante a gestão do agronegócio, já que eles podem ser úteis e de importância econômica, ou seu acúmulo pode causar impactos ambientais severos. A agregação de valor a materiais considerados menos valiosos sob o ponto de vista econômico ou nutricional constitui uma alternativa eficaz no que diz respeito à sustentabilidade da agroindústria. Bioenergia, indústria alimentícia e nanobiotecnologia são apenas alguns exemplos de setores que se beneficiam de subprodutos agropecuários, esta última em particular da biomassa obtida a partir deles e utilizada em rotas de síntese verde.

Dentre os subprodutos agropecuários que podem servir como matérias primas para o desenvolvimento de processos nanobiotecnológicos, em particular rotas de síntese verde de NPMs, destacam-se: o sangue, as penas, as carapaças, as escamas, os pelos, os ossos e as cascas de ovos provenientes da pecuária; e os bagaços, as fibras, as serragens, os farelos, as cascas e as palhas provenientes da agricultura. $\mathrm{O}$ interesse nesses materiais se deve à riqueza de moléculas como as proteínas, os peptídeos, os aminoácidos, os carboidratos, os ácidos nucleicos e as vitaminas. Além de fontes de moléculas que podem ser utilizadas na síntese de NPMs, os subprodutos agropecuários podem ser fontes de princípios ativos com atividades antibióticas, biocidas, antioxidantes, anticâncer, dentre outras, que podem atuar sinergicamente com as NPMs.

Outra fonte inesgotável de matéria-prima para rotas de síntese verde são os diversos produtos agropecuários primários (bactérias, leveduras, grãos, leite e outros). Estes apresentam a produção de uma ampla gama de moléculas, algumas das quais capazes de promover processos de oxirredução, como é o caso de diversas enzimas (como as redutases) e metabólitos (como o peróxido de hidrogênio). De fato, quando expostos a essas moléculas, diversos metais, a partir de seus cloretos, nitratos, sulfatos, entre outras 
formas, podem ser convertidos em NPMs empregadas em aplicações biotecnológicas que vão desde o controle de pragas e patógenos até o desenvolvimento de nanocatalisadores e sistemas de biorremediação para o tratamento de efluentes; além de diversas aplicações biomédicas voltadas para o tratamento e diagnóstico de doenças.

\subsection{SÍNTESE VERDE DE NANOPARTÍCULAS METÁLICAS POR BIOMOLÉCULAS}

Tipicamente, a síntese verde de NPMs envolve a redução química de um sal metálico na presença de um reagente redutor, o qual pode também, atuar como agente estabilizante na síntese, revestindo as NPMs. Uma vasta gama de biomoléculas atuam como agentes redutores em rotas de síntese verde, dentre as quais os polissacarídeos, as proteínas, os peptídeos, os aminoácidos, os ácidos nucleicos e as vitaminas.

\subsubsection{Polissacarídeos}

Polissacarídeos são polímeros de carboidratos formados por longas cadeias de unidades de monossacarídeos unidos entre si por ligações glicosídicas. Uma vasta gama de grupos funcionais podem estar presentes nessas biomoléculas, incluindo grupos hidroxila e extremidade hemiacetal, os quais são capazes de reduzir sais precursores de NPMs, como já demonstrado para o ouro ${ }^{21}$. A extremidade redutora de polissacarídeos também pode ser utilizada para introduzir um grupo funcional amina capaz de estabilizar $\mathrm{NPMs}^{22}$. Foi demonstrado que carboidratos com grupos aminados se ligam fortemente à superfície de nanopartículas de ouro e prata (NPOs e NPPs, respectivamente), conferindo-lhe uma superfície hidrofílica ${ }^{23}$. Dentre os polissacarídeos utilizados na síntese verde de NPMs podem ser citados o ácido hialurônico, a heparina e a quitosana.

$\mathrm{O}$ ácido hialurônico $(\mathrm{AH})$ é um polissacarídeo linear de massa molecular alta e amplamente distribuído em tecidos conjuntivos de animais, sendo constituído por unidades de ácido glucorônico e $\mathrm{N}$-acetil glicosamina ${ }^{24}$. O $\mathrm{AH}$ é utilizado em diversas aplicações terapêuticas devido à alta compatibilidade biológica ${ }^{25}$. Nesse sentido, é crescente o interesse em utilizá-lo para o desenvolvimento e síntese de sistemas nanoparticulados, dentre eles na síntese de NPMs. O AH foi utilizado como agente redutor e estabilizante 
na formação de NPOs (nanopartículas de ouro/ácido hialurônico - Au-AH) e NPPs (nanopartícula de prata/ácido hialurônico - Ag-AH), as quais apresentaram tamanhos que variaram de $5 \mathrm{~nm}$ a $30 \mathrm{~nm}^{26}$. Ag-AH exibiu potente atividade antimicrobiana contra a bactéria gram-positiva Staphyloccocus aureus e atividade moderada contra a bactéria gram-negativa Escherichia coli, apresentando potencial aplicação na terapêutica antibacteriana ${ }^{27}$.

Heparina é um polissacarídeo sulfatado pertencente à família das glicosaminoglicanas. Devido ao seu caráter aniônico, é possível utilizar esta molécula como agente redutor e estabilizante na síntese de NPPs. A abundância de grupos sulfonados presentes na molécula promove a redução de íons $\mathrm{Ag}^{+}$, possibilitando a formação de $\mathrm{NPMs}^{28}$. Além disso, foi demonstrado que a heparina pode atuar no controle da nucleação e estabilização, modulando o tamanho e a forma de NPPs ${ }^{28}$.

A quitosana é um polissacarídeo biodegradável de $\mathrm{N}$-acetil-D-glicosamina e D-glicosamina, obtido pela desacetilação alcalina da quitina, componente importante do exoesqueleto de invertebrados como caranguejos, lagostas, camarões e insetos, e constituindo, portanto, um subproduto importante obtido a partir desses organismos ${ }^{29}$. Por ser considerado um biomaterial atóxico, biodegradável e biocompatível, a quitosana é utilizada em diversos sistemas nanoestruturados ${ }^{30}$. Recentemente, essa molécula foi utilizada como agente redutor e estabilizante na síntese verde de NPPs com atividade antimicrobiana. A formação dessas NPPs ocorre por meio da oxidação dos grupos hidroxila da molécula de quitosana na presença de íons de prata ${ }^{31}$.

\subsubsection{Proteínas, peptídeos e aminoácidos}

A compreensão dos mecanismos bioquímicos por meio dos quais as proteínas propiciam a formação de NPMs tem sido demonstrada com sucesso. Proteínas são utilizadas na síntese de NPMs devido à sua capacidade de interagir com íons inorgânicos, e essas interações são determinantes no tamanho das partículas. A formação de NPOs foi investigada utilizando albumina humana e bovina, as quais apresentaram diâmetros médios de 3,4 nm e $3,5 \mathrm{~nm}$, respectivamente ${ }^{32}$. No mesmo estudo, verificou-se que o tempo de síntese aumenta à medida que a temperatura de fusão da proteína aumenta, indicando a influência da temperatura no período de nucleação e crescimento das NPOs.

Estudos recentes demonstram o uso de pequenos peptídeos como agentes redutores na formação de NPMs, desempenhando um papel-chave no 
processo de nucleação e crescimento de $\mathrm{NPOs}^{33}$. Além disso, tem sido adotada uma abordagem de inspiração biológica para produzir NPMs utilizando proteínas e peptídeos que ocorrem na natureza como modelos para seleção de peptídeos; ou essas moléculas são racionalmente desenhadas para controlar a formação de nanopartículas ${ }^{34}$. Nesse sentido, vários peptídeos multifuncionais foram desenvolvidos para sintetizar NPOs com diferentes morfologias e com tamanhos controlados em função da colocação estratégica de resíduos de aminoácidos selecionados na sequência peptídica ${ }^{33}$.

Estudos indicam que as unidades constituintes de macromoléculas podem representar uma base para nanofabricação biológica genuína ${ }^{35,36}$. Logo, aminoácidos podem exercer influência sobre interações específicas entre as biomoléculas e os metais. Sendo assim, pequenas moléculas de D- ou L-aminoácidos podem controlar o tamanho e a forma das estruturas durante a formação de NPMs ${ }^{35}$.

Aminoácidos, constituintes primários das proteínas, apresentam grupos laterais reativos. Quando em meio aquoso, tornam-se íons dipolares, agindo como ácidos (doadores de prótons) ou bases (receptores de prótons). Assim, os aminoácidos são capazes de reduzir íons de ouro, prata, ferro e outros. Os grupos amina e carboxila dos aminoácidos na superfície das NPMs estabilizam-nas em suspensão, além de ancorá-las virtualmente a qualquer superfície biológica por meio de interações polivalentes.

L-3,4-dihidroxifenilalanina (L-DOPA) foi utilizada como agente redutor na síntese de NPOs com potencial aplicação biomédica ${ }^{37}$. Wang e colaboradores $^{38}$ demonstraram a formação de nanopartículas magnéticas, com diâmetro de $4 \mathrm{~nm}$ a $80 \mathrm{~nm}$, obtidas a partir da redução de íons de ferro pelo aminoácido arginina. As propriedades das NPMs, quando combinadas com as suas toxicidades, poderiam ser utilizadas para produzir nanossistemas com as mais diversas aplicações, como, por exemplo, antibacterianos, antifúngicos, antivirais, antitumorais e carreadores de fármacos ${ }^{39}$.

\subsection{3 Ácidos nucleicos}

A síntese de NPMs utilizando ácidos nucleicos ou nucleotídeos é considerada um campo recente ${ }^{40}$. Foi demonstrado que essas biomoléculas e suas unidades fundamentais são capazes de modular o tamanho e propriedades físico-químicas das $\mathrm{NPMs}^{41}$. Os ácidos desoxirribonucleico (DNA) e ribonucleico (RNA) consistem em cadeias de unidades monoméricas, denominadas nucleotídeos, ligados entre si por ligações fosfodiéster. A síntese de 
nanopartículas também pode ser realizada utilizando os blocos de construção dos ácidos nucleicos, ou seja, por nucleotídeos e nucleosídeos.

Os efeitos de diferentes moléculas de DNA com o mesmo comprimento de cadeia foram investigados durante a síntese de NPOs, resultando na formação de NPMs esféricas e em forma de flor, indicando que moléculas de DNA desempenham papel importante no controle da morfologia ${ }^{42}$. Moléculas de RNA são apontadas como um excelente modelo, capaz de adotar formas estáveis e bem definidas e altamente dependentes de sua sequência. Devido a esse fato, essas moléculas são exploradas em técnicas in vitro visando à seleção de sequências de RNA que apresentam a capacidade de estabilizar a nucleação e a formação de nanopartículas de paládio hexagonais ${ }^{43}$.

\subsubsection{Vitaminas}

O ácido ascórbico (vitamina C) é conhecido por sua propriedade antioxidante, bem como pela biodegradabilidade, biocompatibilidade, baixa toxicidade e alta solubilidade em água. Devido a essas características, o ácido ascórbico foi utilizado para sintetizar NPMs. Um estudo recente avaliou a síntese e estabilização de NPOs à temperatura ambiente, verificando que as partículas apresentaram formatos esféricos, com uma estreita faixa de distribuição de diâmetros médios $(31 \pm 5,36 \pm 6$ e $40 \pm 5 \mathrm{~nm})$, e que sua estabilidade poderia ser controlada pelo ajuste de $\mathrm{pH}$ do meio reacional ${ }^{44}$.

A riboflavina (vitamina $\mathrm{B}_{2}$ ) também foi utilizada como agente redutor e de proteção, devido à sua alta solubilidade em água, biodegradabilidade e baixa toxicidade em comparação com outros agentes redutores. Em rota de síntese verde utilizando a vitamina $B_{2}$ com íons de ouro ou platina à temperatura ambiente, sem a utilização de agente dispersante, ocorreu a formação de nanoesferas, nanofios e nanobastões ${ }^{45}$. Adicionalmente, o tamanho médio das

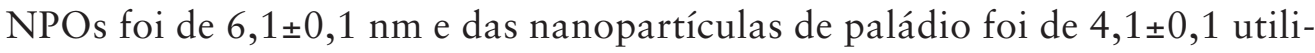
zando rotas de síntese semelhantes. Também foi demonstrado que a forma e tamanho das NPMs são dependentes do solvente utilizado na síntese ${ }^{46}$.

\subsection{SÍNTESE VERDE DE NANOPARTÍCULAS METÁLICAS POR BACTÉRIAS}

Bactérias são muito utilizadas para a biossíntese de NPMs (Tabela 26.1). Os mecanismos que atuam na formação de NPMs por bactérias são 
diversificados, podendo envolver a internalização de alguns íons, que sofrem redução no meio citoplasmático (ou periplasmático, em alguns casos), ou também podem ser reduzidos no exterior da célula, seja pela ação de metabólitos secretados ou pela ação de moléculas existentes na superfície externa da bactéria (Figura 26.2).

Algumas bactérias apresentam NPMs de forma natural, que fazem parte da sua vida no meio ambiente. Bactérias magnetotáticas (BMT) possuem naturalmente em seu interior magnetossomos, nanoestruturas formadas principalmente por óxido de ferro e sulfeto de ferro $\left(\mathrm{Fe}_{3} \mathrm{O}_{4}\right.$ e $\mathrm{Fe}_{3} \mathrm{~S}_{4}$, respectivamente) que permitem que esses organismos se direcionem por meio do campo geomagnético ${ }^{67}$.

As BMTs são capazes de biofabricar nanopartículas a partir de outros metais. Magnetospirillum gryphiswaldense (MSR-1), por exemplo, podem formar NPOs esféricas em sua superfície por meio de biossorção. O diâmetro das NPMs é diretamente proporcional à concentração inicial de metal e ao valor do $\mathrm{pH}$ do meio no qual as bactérias se encontram (na faixa de 1,5 a 4,0). O mecanismo responsável pela formação ainda é desconhecido, mas é possível que se dê por meio de proteínas de superfície ${ }^{60}$. A mesma bactéria também pode sintetizar partículas anisotrópicas (alongadas) de telúrio em seu meio intracelular. O sistema de cristalização ainda está sendo estudado, mas pode envolver várias enzimas, e é possível que o íon de telúrio atue como aceptor final em rotas de metabolismo anaeróbico. A concentração inicial do metal afeta quanto poderá ser absorvido pelas células, pois concentrações muito altas tendem a inibir o crescimento de M. gryphiswaldense ${ }^{61}$.

Tabela 26.1 Síntese verde de nanopartículas metálicas utilizando bactérias

\begin{tabular}{ccccc}
\hline ORGANISMO & ION METÁLICO & DIÂMETRO (NM) & FORMA & REFERÊNCIA \\
\hline Acinetobacter calcoaceticus & Prata & 8 a 12 & Esférica & 47 \\
\hline Aeromonas hydrophila & Titânio & 40,5 & Esférica & 48 \\
\hline Anabaena flos-aquae & Ferro & $103 \times 20$ & Bastão & 49 \\
\hline Bacillus amyloliquefaciens & Prata & 14,6 & Circular/triangular & 50 \\
\hline Bacillus funiculus & Prata & 10 a 20 & Esférica & 51 \\
\hline Bacillus sp. & Prata & 5 a 15 & Esférica & 52 \\
\hline Bacillus subtilis & Níquel & - & Folha & 53 \\
\hline Brevibacterium casei & Cádmio & 10 a 30 & Esférica & 54 \\
\hline Brevibacterium casei & Prata & 10 a 50 & Esférica & 55 \\
\hline Brevibacterium casei & Ouro & 10 a 50 & Esférica & 55 \\
\hline Calothrix pulvinata & Ferro & $128 \times 11$ & Bastão & 49
\end{tabular}




\begin{tabular}{ccccc}
\hline ORGANISMO & ION METÁLICO & DIÂMETRO (NM) & FORMA & REFERÊNCIA \\
\hline Escherichia coli & Ouro & 50 & Circular & 56 \\
\hline Escherichia coli & Cádmio/Telúrio & 3 a 6 & Cúbica & 57 \\
\hline Geobacillus sp. (ID17) & Ouro & 10 a 20 & Hexagonal & 58 \\
\hline Geobacter sulfurreducens & Paládio & $<5$ & - & 59 \\
\hline Magnetospirillum gryphiswaldense & Ouro & 10 a 40 & Esférica & 60 \\
\hline Magnetospirillum gryphiswaldense & Telúrio & $15 \times 200$ & Alongada & 61 \\
\hline Pseudomonas aeruginosa & Prata & $6,3 \pm 4,9$ & Esférica/discoide & 62 \\
\hline Pseudomonas aeruginosa & Paládio & $22,1 \pm 6,2$ & Poligonal & 62 \\
\hline Pseudomonas aeruginosa & Ferro & $20,5 \pm 5,3$ & Laminar & 62 \\
\hline Pseudomonas aeruginosa & Ródio & $2,1 \pm 0,9$ & Irregular & 62 \\
\hline Pseudomonas aeruginosa & Níquel & $2,9 \pm 1,2$ & Discreta & 62 \\
\hline Pseudomonas aeruginosa & Rutênio & $8,3 \pm 5,4$ & Esférica/discoide & 62 \\
\hline Pseudomonas aeruginosa & Platina & 450 & Discoide & 62 \\
\hline Pseudomonas aeruginosa & Cobalto & 550 & Laminar & 62 \\
\hline Pseudomonas aeruginosa & Lítio & 750 & Circular & 62 \\
\hline Pseudomonas stutzeri & Cobre & 8 a 15 & Esférica & 63 \\
\hline Stenotrophomonas maltophilia & Prata & 93 & Cúbica & 64 \\
\hline Streptomyces albidoflavus & Prata & 10 a 40 & Esférica & 65 \\
\hline Streptomyces coelicolor & Prata & 50 & Irregular & 66 \\
\hline & & & &
\end{tabular}

Além de bactérias que produzem naturalmente NPMs, algumas das bactérias mais utilizadas para a síntese de NPMs são reconhecidas por microbiologistas devido às suas patogenicidades a seres humanos, animais e plantas ${ }^{68,69}$.

Escherichia coli (K12) produz NPOs, que se formam por meio da redução de íons pela ação de proteínas de membranas extracelulares, as quais também possuem importância na estabilização ${ }^{56}$. E. coli superexpressando genes envolvidos na síntese de glutationa formam NPMs intracelulares de cádmio e telúrio (Cd e Te). Nesse caso, a glutationa atua como agente redutor desses metais e estabiliza as NPMs ${ }^{57}$.

Streptomyces é um gênero de bactérias muito utilizado para síntese de NPPs. S. albidoflavus pode produzir NPMs que apresentam aminoácidos e peptídeos em sua superfície, sendo formadas tanto em meio extracelular como intracelular ${ }^{65}$. O pigmento produzido por $S$. coelicolor foi utilizado como agente redutor de íons de prata após exposição a micro-ondas. Resultados indicam que o pigmento forma uma camada circundante nas NPMs, impedindo a sua aglomeração e permitindo a estabilização ${ }^{66}$.

O extrato de livre de células de Acinetobacter calcoaceticus também promove a formação de NPPs. As NPMs se apresentam incorporadas por uma matriz orgânica composta por agentes redutores e estabilizantes secretados 
pelas células. Variações no meio reacional de síntese, como temperatura e concentração de sal metálico, mostraram que as NPMs podem ter a quantidade e a morfologia alteradas ${ }^{47}$.

NPPs produzidas extracelularmente, com uma cobertura de peptídeos, podem ser biofabricadas por Stenotrophomonas maltophilia. As NPMs produzidas são estáveis e possuem taxa de difusão alta. Os autores também observaram que quanto menor o tamanho da NPM, maior é a sua cinética de liberação no meio extracelular ${ }^{64}$.

Uma espécie pertencente ao gênero Geobacillus (ID17) produz NPOs intracelularmente. O estudo da superfície dessas partículas revelou que o agente que as reveste possui um grupo amina aromático, sendo possivelmente uma enzima com atividade de redutase. O processo de formação de NPMs em micro-organismos que possuem tais enzimas pode ser realizado devido à transferência de elétrons de nicotinamida-adenina-dinucleotídio (NADH) que reduzem íons metálicos ${ }^{58}$.

Aeromonas hydrophila é uma bactéria formadora de nanopartículas de titânio no meio extracelular, devido à atividade redutora e estabilizante de alguns de seus metabólitos, que revestem as NPMs. A principal molécula envolvida na biofabricação é a glicil-L-prolina, possivelmente responsável pela desidratação de hidróxido de titânio ${ }^{48}$.

Nanopartículas de cobre podem ser sintetizadas pela bactéria Pseudomonas stutzeri, e apresentam uma cobertura orgânica que protege a partícula contra oxidação ${ }^{63}$. Srivastava e Constanti ${ }^{62}$ utilizaram P. aeruginosa para sintetizar diversas NPMs (Ag, Pd, Fe, Rh, Ni, Ru, Pt, Co, e Li) na ausência de meio de cultura. De todos os metais utilizados, apenas o cobalto e o lítio formaram partículas intracelulares. Isso sugere que esse micro-organismo possui um mecanismo de seleção único, que permite a internalização de alguns íons enquanto outros são reduzidos em suas proximidades. Dados obtidos por espectroscopia de infravermelho por transformada de Fourier (FTIR) sugerem que algumas aminas primárias e secundárias são as responsáveis pela síntese extracelular de NPMs, o que não é observado para nanopartículas intracelulares.

O gênero Bacillus é utilizado na síntese de vários tipos de nanopartículas. B. subtilis é capaz de formar uma rede de óxido de grafeno e sulfeto de níquel ${ }^{53}$. B. funiculus e $B$. amyloliquefaciens foram utilizados na síntese de NPPs, por síntese extracelular ${ }^{51}$ e na presença de radiação solar ${ }^{50}$, respectivamente. Pugazhenthiran e colaboradores ${ }^{52}$ isolaram um Bacillus sp resistente a prata e o utilizaram para síntese periplasmática de NPPs (espaço entre a membrana externa e a citoplasmática). 
Geobacter sulfurreducens é biorredutora de uma variedade de íons metálicos, dentre eles o paládio. Nanopartículas de paládio produzidas por essa bactéria se localizam no espaço periplasmático, possivelmente devido à distribuição e às propriedades de algumas enzimas redutoras. É interessante notar que, para essa reação, um aumento na proporção de células em relação à quantidade inicial de íons ocasiona um aumento na quantidade de nanopartículas sintetizadas com um diâmetro menor ${ }^{59}$.

Brevibacterium casei biossintetiza nanopartículas fluorescentes de cádmio (CdS). Essa síntese ocorre de maneira mais eficiente quando os organismos incubados com o sal metálico se encontram na fase estacionária de crescimento. Fatores como pH e concentração inicial de íons interferem na quantidade de NPMs sintetizadas ${ }^{54}$. Esse micro-organismo também é capaz de produzir NPPs e NPOs. As evidências experimentais mostram que os agentes biorredutores nessa bactéria são proteínas secretadas ${ }^{55}$.

Já micro-organismos fotossintetizantes, como as cianobactérias Calothrix pulvinata e Anabaena flos-aquae, são capazes de produzir em meio intracelular nanobastões de ferro ${ }^{49}$. Para a reação, Brayner e colaboradores ${ }^{49}$ utilizaram concentrações equimolares de íons $\mathrm{Fe}^{2+}$ e $\mathrm{Fe}^{3+}$ para formação das nanoestruturas, pois foi verificado que os organismos resistiam melhor a essa situação de cultura.

Como foi visto, a abundante biodiversidade de bactérias apresenta grande potencial para sintetizar NPMs com as mais diversas aplicações. Algumas das rotas de formação das NPMs já foram elucidadas; contudo, diversos mecanismos celulares, bioquímicos e moleculares, que estão envolvidos em algumas sínteses, ainda são pouco conhecidos. Para isso, vários fatores, como meios de cultivo, condições de crescimento, extração de moléculas, concentrações iônicas e tempo de reação, por exemplo, podem ser investigados e explorados a fim de tentar elucidar esses mecanismos, bem como aperfeiçoar e padronizar as rotas de síntese de NPMs utilizando esses micro-organismos.

\subsection{SÍNTESE VERDE DE NANOPARTíCULAS METÁLICAS POR ALGAS}

O ecossistema aquático ocupa aproximadamente $70 \%$ da superfície da Terra e contém uma expressiva biodiversidade e ampla variabilidade de compostos a serem explorados. Esses recursos biológicos são fontes ricas de agentes redutores (incluindo alcaloides, compostos fenólicos e proteínas), precursores de moléculas como a sílica, o cálcio, a quitosana e também de 
agentes estabilizadores como os polissacarídeos, os lipídeos, os peptídeos, entre outros ${ }^{70}$. Entretanto, apesar de o ecossistema aquático apresentar um alto potencial para a síntese de NPMs o seu uso é pouco explorado ${ }^{9,70}$. As algas são importantes representantes do ecossistema aquático e apresentam uma grande diversidade na sua composição química, que é influenciada por mudanças ambientais (temperatura, nutrientes, salinidade, entre outros), bem como por interações bióticas ${ }^{71}$. Nesse contexto, as algas são fontes biológicas para a síntese de NPMs (Tabela 26.2).

Tabela 26.2 Síntese verde de nanopartículas metálicas utilizando algas

\begin{tabular}{ccccc}
\hline ORGANISMO & ION METÁLICO & DIÂMETRO (NM) & FORMA & REFERÊNCIA \\
\hline Chlamydomonas reinhardtii & Prata & 5 a 35 & Circular/retangular & 72 \\
\hline Chlorella vulgaris & Prata & $<15$ & - & 73 \\
\hline Cladosiphon okamurnus & Ouro & 8 a 10 & Esférica & 74 \\
\hline Diadesmis gallica & Ouro & 22 & Esférica & 75 \\
\hline Gelidiella acerosa & Prata & 22 & Esférica & 76 \\
\hline Kiellamaniella crassifólia & Ouro & 8 a 10 & Esférica & 74 \\
\hline Nannochloropsis oculata & Prata & $<15$ & - & 73 \\
\hline Navicula atomus & Ouro & 9 & Esférica & 75 \\
\hline Sargassum wightii & Ouro & 5 a 15 & Laminar & 77 \\
\hline Sargassum wightii & Ferro & 18 & Cúbica & 78 \\
\hline Ulva fasciata & Prata & 9 a 19 & - & 79 \\
\hline
\end{tabular}

NPPs foram sintetizadas utilizando a alga Sargassum wightii e apresentaram atividade antimicrobiana para Staphylococcus aureus, Escherichia coli $\mathrm{e}$ Pseudomonas aeruginosa ${ }^{77,80}$. Um controle significativo para Xanthomonas campestri sp v. Malvacearum foi obtido por NPPs sintetizadas a partir de extratos de Ulva fasciata ${ }^{79}$. A macroalga de coloração vermelha Gelidiella acerosa tem uma significativa importância econômica devido à alta qualidade do seu ágar. Além disso, essa alga tem o potencial de sintetizar NPPs com atividade fungicida para Mucor indicus, Trichoderma reeseii, Fusarium dimerum e Humicola insolens ${ }^{76}$. Adicionalmente, as microalgas Navicula atomus e Diadesmis gallica podem sintetizar, in vivo, $\mathrm{NPOs}^{75}$.

A biossíntese de NPPs por Chlamydomonas reinhardtii in vivo foi mais rápida quando comparada com a síntese in vitro (extrato). Nesse caso, a 
síntese in vivo foi localizada no citoplasma, no núcleo e no flagelo ${ }^{72}$. Visando demonstrar a possível ação de proteínas nessa síntese, foram testados extratos com e sem proteínas. Como resultado, a fração livre de proteínas apresentou uma síntese lenta, com a obtenção de NPMs maiores, sugerindo a participação dessa classe de biomoléculas na síntese ${ }^{72}$.

O fucoidan é um polissacarídeo obtido a partir de algas marinhas Cladosiphon okamurnus (o-fucoidan) e Kjellamaniella crassifolia (t-fucoidan), sendo utilizado para reduzir e estabilizar NPOs ${ }^{74}$. NPPs foram sintetizadas a partir de extratos aquosos de polissacarídeos provenientes das algas Pterocladia capillacae, Jania rubins, Ulva faciata e Colpmenia sinusa. As suspensões coloidais das NPMs formadas apresentaram atividade antimicrobiana $^{81}$.

A contaminação por metais pesados em ambientes aquáticos constitui um sério problema, e uma estratégia utilizada para minimizá-la é o uso de microalgas para a biorremediação. As microalgas são capazes de sequestrar metais pesados por adsorção e também pela produção de fitoquelatinas (as quais são produzidas, principalmente, por algas, plantas e fungos) e estão relacionadas com a detoxificação de metais pesados presentes no ambiente pela formação de um complexo estável metal-fitoquelatina, o qual se constitui como uma NPM ${ }^{9}$.

Desse modo, as algas apresentam potencial para sintetizar NPMs com aplicações promissoras. Entretanto, os mecanismos envolvidos na síntese de NPMs por algas são escassos e não há um consenso sobre quais transcorreriam em cada situação.

\subsection{SÍNTESE VERDE DE NANOPARTÍCULAS METÁLICAS POR FUNGOS}

Fungos são seres micro ou macroscópicos capazes de exercer diversos impactos no meio ambiente e no ser humano, tanto de forma negativa (doenças) quanto positiva (produção de alimentos e antibióticos) ${ }^{82}$. Devido aos componentes biológicos presentes nas suas estruturas celulares, envolvidos em seus processos metabólicos, pode haver potencial para bioacumulação e tolerância a metais. Por isso, os fungos estão presentes em diversos estudos sobre geração biológica de NPMs, uma vez que podem ser obtidos em larga escala, além de propiciar viabilidade econômica para produção ${ }^{12}$. Os fungos produzem principalmente proteínas (enzimas secretadas) como potenciais formadores de NPMs (Tabela 26.3). Além disso, podem apresentar formação 
intra ou extracelular de NPMs (Figura 26.2). Exemplos das espécies utilizadas em rotas de síntese verde são Volvariella volvacea, Candida albicans, Aspergillus fumigatus, Trichoderma harzianum, Fusarium oxysporum e Schizosaccharomyces pombe $e^{18,19,83-86}$.

Tabela 26.3 Síntese verde de nanopartículas metálicas utilizando fungos

\begin{tabular}{ccccc}
\hline ORGANISMO & ION METÁLICO & DIÂMETRO (NM) & FORMA & REFERÊNCIAS \\
\hline Candida glabrata & Cádmio & 2 & Esférica & 87 \\
\hline Levedura MKY3 & Prata & 2 a 5 & Hexagonal & 88 \\
\hline Saccharomyces cerevisiae & Antimônio & 2 a 10 & Esférica & 89,90 \\
\hline Schizosacharomyces & Cádmio & 1 a 1,5 & Hexagonal & 83 \\
\hline Yarrowia lipolytica & Ouro & 15 & Hexagonal/triangular & 89,91 \\
\hline Fusarium oxysporum & Zinco & 42 & - & 92 \\
\hline Fusarium oxysporum & Silício & 5 a 15 & Quase esférica & 89,93 \\
\hline Fusarium oxysporum & Titânio & 6 a 13 & Esférica & 89,93 \\
\hline Fusarium oxysporum & Platina & 10 a 100 & Variada & 94 \\
\hline Fusarium oxysporum & Prata & 16 a 30 & - & 95 \\
\hline Aspergillus fumigatus & Prata & 5 a 25 & Esférica/triangular & 85 \\
\hline Trichoderma harzianum & Prata & 5 & Quase esférica & 96 \\
\hline Coriolus versicolor & Prata & 25 a 75 & Esférica & 97 \\
\hline Volveriella volvacea & 0uro/Prata/Ouro-Prata & 15 a 150 & Triangular/quase esférica/hexagonal & 18 \\
\hline
\end{tabular}

\subsubsection{Fungos ascomicetos}

Estudos mostraram que Fusarium oxysporum produz NPPs extracelularmente, provavelmente por meio de proteínas, dentre elas uma redutase dependente de NADH. Contudo, também foi relatado que essa enzima não está presente em todos os fungos, podendo justificar o estudo em que $F$. moniliforme não participa da formação intra ou extracelular de NPPs ${ }^{84,98}$. Outro estudo observou a redução de íons metálicos na presença de redutase dependente de nitrato e uma quinona de transporte extracelular, assim como síntese de NPMs utilizando enzima purificada de F. osysporum, fitoquelatina 
e 4-hidroxiquinolina; mas na ausência de um desses componentes não ocorre produção de $\mathrm{NPMs}^{98,99}$. Em estudo recente, nanopartículas esféricas de 42 $\mathrm{nm}$ de sulfeto de zinco $(\mathrm{ZnS})$ foram sintetizadas utilizando F. oxysporum ${ }^{92}$. Em outro estudo, nanopartículas de silício e de titânio com $5 \mathrm{~nm}$ a $15 \mathrm{~nm}$ e $6 \mathrm{~nm}$ a $13 \mathrm{~nm}$, respectivamente, foram produzidas extracelularmente com F. oxysporum em contato com complexos aniônicos $\mathrm{SiF}_{6}{ }^{2-}$ (hexafluoreto de silício iônico) e $\mathrm{TiF}_{6}{ }^{2-}$ (hexafluoreto de titânio iônico). As nanopartículas de titânio foram formadas à temperatura ambiente, e as de silício a $300{ }^{\circ} \mathrm{C}^{89,93}$. F. oxysporum também produziu nanopartículas de platina na presença de ácido hexacloplatínico. Interessantemente, houve a produção intracelular, além da formação extracelular de NPMs. O tamanho das NPMs variou entre $10 \mathrm{~nm}$ e $100 \mathrm{~nm}$ com formas hexagonais, pentagonais, esféricas, quadradas e retangulares ${ }^{94}$. Um estudo mais recente mostrou a produção de NPPs com tamanho entre $16 \mathrm{~nm}$ e $30 \mathrm{~nm}$ pelo fungo F. oxysporum, as quais apresentaram atividade contra fungos e bactérias ${ }^{95}$.

Aspergillus fumigatus também realiza síntese extracelular de NPMs utilizando filtrado de células, com NPPs dispersas com diâmetro de $5 \mathrm{~nm}$ a $25 \mathrm{~nm}$ e com forma esférica e triangular ${ }^{85}$. Em outro estudo, Trichoderma harzianum quando em contato com íons prata mostrou acúmulo de NPPs na superfície de sua parede celular. Após banho de ultrassom, as NPMs em suspensão apresentaram-se razoavelmente monodispersas, cristalinas e quase esféricas, com um diâmetro médio de aproximadamente $5 \mathrm{~nm}^{96}$.

As leveduras são fungos que possuem um citoplasma circundado por um envelope composto de membrana plasmática, espaço periplasmático e parede celular. Essa estrutura celular apresenta moléculas como proteínas, polissacarídeos, lipídeos, ácidos nucleicos e metabólitos que tornam as leveduras bastante utilizadas em bioprocessos. A concentração dessas moléculas atua diretamente nas rotas de síntese verde de NPMs envolvendo leveduras $^{98}$, variando de acordo com a espécie e sendo geralmente influenciada pelas condições de crescimento ${ }^{100}$.

O fato de proteínas como enzimas transferirem elétrons para íons metálicos, reduzindo-os, faz dessas biomoléculas as principais responsáveis pelo uso de leveduras na síntese de $\mathrm{NPMs}^{101}$. Além disso, grande parte das leveduras tem a capacidade de acumular metais por mecanismos físicos e biológicos, ligando-os a metabólitos ou biopolímeros específicos e possibilitando o seu acúmulo de uma maneira dependente de metabolismo ${ }^{86,102}$. Por esse motivo, leveduras promovem a formação de NPMs por rota intracelular, extracelular ou mesmo ligado à parede celular (Figura 26.2) a partir de íons de prata, ouro, zircônio, titânio, ferro, cádmio, entre outros ${ }^{103}$. 
Krumov e colaboradores ${ }^{104}$ mostraram que a formação de nanocristais de CdS, por exemplo, depende da especificidade da cepa e das condições de cultivo das leveduras. Nesse mecanismo, as macromoléculas contribuintes são a glutationa (GSH), metalotioninas e fitoquelatinas. A biomineralização do cádmio pelas leveduras Schizosaccharomyces pombe e Candida glabrata evidencia uma biotransformação do metal, na qual íons $\mathrm{Cd}^{2+}$ são sequestrados com pequenos peptídeos seletivos e coprecipitados com enxofre inorgânico, originando clusters de CdS atóxicos ${ }^{104}$.

Em cultura de Candida glabrata, a presença de íons $\mathrm{Cd}^{2+}$ levou à formação intracelular de pontos quânticos (semicondutores) de CdS. Essas NPMs foram obtidas por neutralização, obtendo-se cristais de CdS monodispersos de forma esférica e ligados a peptídeos com diâmetro aproximado de $2 \mathrm{~nm}^{87}$. As leveduras do gênero Schizosaccharomyces também produzem nanopartículas de CdS intracelularmente quando em contato com solução de cádmio e com dimensões em torno de $1 \mathrm{~nm}$ a 1,5 nm. Essas NPMs foram destinadas à fabricação de um diodo com a junção de poli ( $p$-fenilenovinileno) com características consideradas ideais para o material ${ }^{83}$.

Yarrowia lipolytica (NCIM 3589) foi utilizada na síntese de NPOs, e análises por microscopia eletrônica de varredura (MEV) e de transmissão (MET) mostraram que as NPMs produzidas estavam associadas à parede celular da levedura. O estudo mostrou a formação de NPOs hexagonais e triangulares por causa da nucleação na superfície das células que deram origem à cor dourada na região do visível $(540 \mathrm{~nm})$ em $\mathrm{pH}$ 7,0 e cores rosa e roxo em pH 9,0, com um diâmetro médio de aproximadamente $15 \mathrm{~nm}^{89,91}$. Em contrapartida, Saccharomyces cerevisiae, levedura utilizada como fermento de pães, produziu nanopartículas de óxido de antimônio $\left(\mathrm{Sb}_{2} \mathrm{O}_{3}\right)$ à temperatura ambiente. As NPMs apresentaram forma esférica com células unitárias cúbicas de face centrada, diâmetro variando entre $2 \mathrm{~nm}$ e $10 \mathrm{~nm}$ e propriedades semicondutoras ${ }^{89,90}$. Em outro estudo, a variedade de levedura MKY3, tolerante à prata, produziu extracelularmente NPPs hexagonais de tamanho entre $2 \mathrm{~nm}$ e $5 \mathrm{~nm}$. As NPMs foram obtidas quando leveduras MKY3 em fase logarítmica de crescimento foram desafiadas com prata solúvel ${ }^{88}$.

Outro estudo mostrou que o rendimento final de nanopartículas de CdS foi determinado pela concentração inicial de glicose no meio de cultura, que está diretamente relacionada com a concentração final de biomassa e o nível de concentração de CdS no meio reacional. Adicionalmente, foi observado que a formação de nanopartículas de CdS depende do momento em que o metal cádmio é disponibilizado para a célula, o que desencadeia uma reação 
proteica devido ao estresse à qual foi submetida. A adição de cádmio no intervalo médio de crescimento até o fim da fase estacionária forneceu maior produção de NPMs. Outro fator a ser considerado para a geração de um melhor rendimento de NPMs é o tempo de reação. Foi observado que uma concentração máxima de cádmio nas células é medida em aproximadamente 24 horas após a adição de cádmio ao meio com a levedura. Contudo, 10 horas após a concentração máxima de cádmio ser alcançada observa-se uma diminuição nos níveis intracelulares ${ }^{87,104}$.

\subsubsection{Fungos basidiomicetos (cogumelos)}

Dentre os cogumelos utilizados em síntese de NPMs está o Coriolus versicolor, o qual sintetiza moléculas capazes de reduzir íons prata e revestir as NPMs. Na síntese, as NPPs se formaram pelo contato do fungo com solução de nitrato de prata, permitindo o acúmulo de NPMs na superfície em um período de 72 horas. Em condições alcalinas os grupos tióis da superfície do fungo tiveram um papel importante na aceleração da síntese à temperatura ambiente. As NPPs apresentaram diâmetro entre $25 \mathrm{~nm}$ e $75 \mathrm{~nm}$, forma esférica por microscopia de força atômica (MFA) e MET, e a análise por FTIR indicou a presença de grupos amino, oriundos de proteínas, provavelmente responsáveis pela estabilidade ${ }^{97}$.

Em outro estudo, foi realizada a síntese extracelular em meio aquoso com extrato do cogumelo comestível Volvariella volvacea como agente redutor e estabilizante de nanopartículas de Au, Ag e Au-Ag. As NPOs apresentaram forma de nanoprismas triangulares, quase esféricos e hexagonais entre $15 \mathrm{~nm}$ e $150 \mathrm{~nm}$ de diâmetro. As NPMs preparadas por corredução de Au-Ag apresentaram apenas uma banda plasmônica devido à liga dos constituintes e apresentaram fotoluminescência e alta cristalinidade. Análises por FTIR mostraram que as NPOs estavam ligadas a proteínas pelos grupos amino livres e as NPPs por meio do grupo carboxilato dos resíduos de aminoácidos ${ }^{18}$.

Como observado pela revisão da literatura na área, existem diversas espécies de fungos que podem ser utilizadas na síntese de NPMs, além de vários íons metálicos que podem ser biorreduzidos. Desse modo, a síntese verde com fungos envolve um sistema microbiológico com capacidade de acumular várias espécies metálicas. Nesse contexto, o êxito na produção de NPMs por fungos está diretamente relacionado com a linhagem, meio de cultivo adequado, tempo de síntese, quantidade de metal e momento de adição do íon 
metálico; fatores que estão diretamente relacionados ao perfil bioquímico de leveduras e demais fungos, juntamente com suas condições de crescimento.

\subsection{SÍNTESE VERDE DE NANOPARTÍCULAS METÁLICAS POR PLANTAS}

A síntese verde de NPMs mediada por plantas, seja utilizando um extrato ou o próprio organismo vivo, é atualmente a mais reportada na literatura $^{13,20}$. As plantas utilizam metabólitos (incluindo flavanoides, terpenoides, saponinas e polifenois) e proteínas para diversos aspectos relacionados à sua fisiologia. Essas mesmas moléculas são as responsáveis por fazer das plantas um dos principais reatores e fornecedores de moléculas para rotas de síntese verde ${ }^{16,105}$. Desse modo, atualmente é aceito que plantas produzam uma gama de metabólitos que podem atuar, possivelmente de maneira sinérgica, na redução de íons metálicos e/ou na estabilização das NPMs. Acredita-se que os principais compostos responsáveis pela redução de íons metálicos por plantas são os aminoácidos, o ácido cítrico, os flavonoides, os compostos fenólicos, os terpenoides, os compostos heterocíclicos, as enzimas, o $\mathrm{CO}_{2}$ intracelular, as proteínas de membrana, os peptídeos, os polissacarídeos, as saponinas, o ácido tânico, entre outros ${ }^{106}$.

O número de publicações relacionadas à síntese verde de NPMs utilizando extratos de plantas tem crescido e, embora o(s) composto(s) da planta que atue $(m)$ na redução e/ou estabilização das NPMs algumas vezes seja $(m)$ identificado(s), o mecanismo específico da síntese verde mediada por plantas ainda não foi estabelecido ${ }^{98,106}$. Isso deriva do fato de que diferentes plantas apresentam composições, concentrações e combinações variadas desses agentes redutores, o que em última instância define a eficiência do extrato na formação de NPMs ${ }^{107}$.

Um número expressivo de espécies de plantas é encontrado na natureza, e muitas são candidatas para síntese de $\mathrm{NPMs}^{13}$. A literatura científica sinaliza para a eficácia no uso de plantas na síntese verde de NPMs, visto que muitos estudos demonstraram o potencial redutor de íons metálicos por extratos de diferentes espécies (Tabela 26.4). Diversas plantas comumente conhecidas já foram utilizadas como fontes geradoras de NPMs, tais como: Medicago sativa (alfafa), Aloe vera (babosa), Glycine max (soja), Camellia sinensis (chá), Syzygium cumini (jamelão), Bauhinia variegata (pata-de-vaca), Cedrus deodara (cedro-do-himalaia), Lonicera japônica (madressilva), Elaeocarpus sphaericus, Sesbania grandiflora, entre outras ${ }^{105,108-112}$. 
Outro aspecto relevante no que concerne à síntese verde de NPMs por plantas é o fato de que diferentes partes vegetais (como por exemplo, folhas, sementes, cascas, raízes e outras) podem produzir partículas com características distintas, e, por esse motivo, devem ser consideradas separadamente. A planta Ocimum sanctum (manjericão-santo) foi utilizada para sintetizar NPPs com diâmetros de $25 \mathrm{~nm}$ a $40 \mathrm{~nm}$ a partir de um extrato feito com as folhas da planta ${ }^{113}$. Sínteses com a mesma planta foram realizadas utilizando extratos de caule e de raiz, mas nesse caso os diâmetros médios das NPMs foram de $10 \mathrm{~nm}$ e $5 \mathrm{~nm}$, respectivamente ${ }^{114}$. Esses dados indicam a diferença nos parâmetros do produto final da síntese de acordo com a parte da planta escolhida para a formação do extrato. Em cada parte da planta há um perfil de fitoquímicos com diferentes concentrações, de acordo com a necessidade de cada tecido e com o tipo de estresse ao qual a planta possa estar submetida (incluindo temperatura e umidade) ${ }^{13}$.

Conforme explicitado, a síntese de NPMs utilizando extratos de diferentes partes de plantas tem sido amplamente explorada. Os extratos derivados das folhas são a escolha mais comum para realizar a síntese verde a partir de plantas, mas o uso do extrato de sementes, cascas, flores, frutos, tubérculos e raízes também foi reportado. Sendo assim, o material de origem (parte da planta), conjuntamente com a época do ano ou local de coleta do extrato da planta, bem como a presença de agentes estressores abióticos (presença de metais, agrotóxicos, entre outros) ou bióticos (presença de pragas ou patógenos), apresenta grande influência na síntese e nas características das NPMs.

Tabela 26.4 Síntese verde de nanopartículas metálicas utilizando extratos de plantas

\begin{tabular}{ccccc}
\hline ORGANISMO & ION METÁLICO & DIÂMETRO & FORMA & REFERÊNCIAS \\
\hline Aloe vera (babosa) & Prata & $15,2 \mathrm{~nm}$ & Esférica & 109 \\
\hline Aloe vera & Ouro & - & Triangular & 109 \\
\hline Aloe vera & Índio & $5 \mathrm{~nm} \mathrm{a} 50 \mathrm{~nm}$ & Cúbica & 131 \\
\hline Acalypha indica & Prata & $20 \mathrm{~nm} \mathrm{a} 30 \mathrm{~nm}$ & - & 132 \\
\hline Anacardium occidentale L. (caju) & Prata & $4 \mathrm{~nm}$ & Esférica & 129 \\
\hline Callicarpa maingayi & Prata & $12,4 \mathrm{~nm}$ & - & 119 \\
\hline Capsicum annumm L. (pimentão) & Prata & $10 \mathrm{~nm} \mathrm{a} 40 \mathrm{~nm}$ & Esférica & 117 \\
\hline Cinnamomum camphora (cânfora) & Paládio & $3,2 \mathrm{~nm} \mathrm{a} 6 \mathrm{~nm}$ & - & 133 \\
\hline Cinnamomum camphora & Prata & $64,8 \mathrm{~nm}$ & - & 116 \\
\hline Cinnamomum camphora & Ouro & $21,5 \mathrm{~nm} \mathrm{a} 23,4 \mathrm{~nm}$ & Triangular/ esférica & 116 \\
\hline Cinnamomum zeylanicum (canela) & Ouro & $25 \mathrm{~nm}$ & Esférica/ prismática & 115 \\
\hline Cinnamomum zeylanicum (canela) & Prata & $31 \mathrm{~nm} \mathrm{a} 40 \mathrm{~nm}$ & Cúbica & 122 \\
\hline
\end{tabular}




\begin{tabular}{ccccc}
\hline ORGANISMO & ION METÁLICO & DIÂMETRO & FORMA & REFERÊNCIAS \\
\hline Cocos nucifera L. (coco) & Ouro & $10 \mathrm{~nm}$ & Esférica & 130 \\
\hline Coriandum sativum (coentro) & Ouro & $6,7 \mathrm{~nm} \mathrm{a} 57,9 \mathrm{~nm}$ & Variada & 134 \\
\hline Cuminum cyminum (cominho) & Ouro & $1 \mathrm{~nm} \mathrm{a} 10 \mathrm{~nm}$ & Esférica & 126 \\
\hline Diospyros kaki (caquizeiro) & Platina & $2 \mathrm{~nm} \mathrm{a} 12 \mathrm{~nm}$ & Cristalina & 135 \\
\hline Gardenia jasminoides (gardênia) & Paládio & $3 \mathrm{~nm} \mathrm{a} 5 \mathrm{~nm}$ & - & 136 \\
\hline Glycine max (soja) & Paládio & $15 \mathrm{~nm}$ & Esférica & 137 \\
\hline Helianthus annuus & Ouro & $30 \mathrm{~nm} \mathrm{a} 50 \mathrm{~nm}$ & - & 127 \\
\hline Medicago sativa (alfafa) & Prata & $5 \mathrm{~nm} \mathrm{a} 51 \mathrm{~nm}$ & Esférica & 125 \\
\hline Mentha piperita (hortelã) & Prata & $90 \mathrm{~nm}$ & Esférica & 138 \\
\hline Mentha piperita & Ouro & $150 \mathrm{~nm}$ & Esférica & 138 \\
\hline Nyctanthes arbortristis & Ouro & $19 \mathrm{~nm}$ & Esférica & 128 \\
\hline Ocimum tenuiflorum (manjericão-pequeno) & Prata & $25 \mathrm{~nm} \mathrm{a} 40 \mathrm{~nm}$ & Esférica & 113 \\
\hline Ocimum sanctum (manjericão-sagrado) & Prata & $5 \mathrm{~nm} \mathrm{e} 10 \mathrm{~nm}$ & Esférica & 114 \\
\hline Papaver somniferum & Prata & $3,2 \mu \mathrm{m} \mathrm{a} \mathrm{7,6} \mathrm{\mu m}$ & Esférica & 124 \\
\hline Prosopis juliflora & Prata & - & Cúbica & 139 \\
\hline Rhododedendron dauricam & Prata & $25 \mathrm{~nm} \mathrm{a} 40 \mathrm{~nm}$ & Esférica & 140 \\
\hline Sebasnia grandiflora & Prata & $10 \mathrm{~nm} \mathrm{a} 25 \mathrm{~nm}$ & Esférica & 112 \\
\hline Sorbus aucuparia & Prata & $16 \mathrm{~nm}$ & Esférica & 141 \\
\hline Sorbus aucuparia & Ouro & $18 \mathrm{~nm}$ & Triangular/ hexagonal & 141 \\
\hline Tamarindus indica L. (tamarindo) & Ouro & $20 \mathrm{~nm} \mathrm{a} 40 \mathrm{~nm}$ & Cristalina & 142 \\
\hline Tephrosia purpurea (índigo-selvagem) & Prata & $20 \mathrm{~nm}$ & Esférica & 143 \\
\hline Trachyspermum ammi & Prata & $87 \mathrm{~nm} \mathrm{a} 998 \mathrm{~nm}$ & Triangular & 124 \\
\hline
\end{tabular}

\subsubsection{Folhas}

De acordo com o potencial redutor das biomoléculas encontradas nos extratos das folhas, pode-se obter NPMs de diferentes formas e tamanhos. Uma pesquisa realizada com síntese verde de NPOs com extrato das folhas de Cinnamomum zeylanicum (canela) mostrou uma relação entre a quantidade de extrato e a forma das NPMs obtidas. Com maior quantidade de extrato, as NPMs adotaram uma forma esférica, enquanto que, com menor quantidade, uma forma prismática ${ }^{115,116}$.

Além da variação das características de NPMs obtidas por diferentes extratos, pode-se variar algumas outras condições da síntese, como tempo de reação, concentração de extrato e/ou íons metálicos, temperatura e $\mathrm{pH}$, visando otimizar o rendimento e rapidez da reação para que ela assemelhe aos padrões típicos de síntese química. O tamanho das NNPs sintetizadas utilizando extrato de Capsicum annuum L. (pimentão) aumentou de acordo com o tempo de reação. A síntese durante 5, 9 ou 13 horas de reação formou 
NPPs com aproximadamente $10 \mathrm{~nm}, 25 \mathrm{~nm}$ e $40 \mathrm{~nm}$, respectivamente ${ }^{117}$. Outro estudo avaliou a eficiência da síntese de NPPs com variações nas temperaturas de reação e utilizando extratos das folhas de Pinus densiflora (pinho-vermelho-japonês), Diospyros kaki (caquizeiro), Gingko biloba, Magnolia kobus e Platanus orientalis. Os resultados indicaram que a síntese com extrato de Magnolia kobus a $95{ }^{\circ} \mathrm{C}$ foi a mais eficiente, capaz de reduzir $90 \%$ do nitrato de prata em apenas 11 minutos $^{118}$. Esse resultado compara-se em eficiência ao uso de compostos químicos convencionais. Sendo assim, vale ressaltar a importância da variação dos parâmetros da síntese para obtenção de NPMs com as características almejadas.

Além da síntese de NPMs a partir de metais nobres, extratos de folhas são utilizados para sintetizar nanopartículas de outros metais com sucesso, como a platina e o paládio ${ }^{106}$. A síntese verde de NPMs também pode ocorrer com a planta in vivo ${ }^{9}$. As plantas respondem ao estresse gerado pela presença de metais por um processo de complexação desses metais via produção de fitoquelantes ou de peptídeos quelantes de metais ${ }^{114}$. Entretanto, esse processo é mais lento e possui o custo alto.

\subsubsection{Casca}

Alguns estudos têm demonstrado a biossíntese de NPMs a partir de extrato da casca. O extrato metanólico da casca de Callicarpa maingayi atua como agente redutor e estabilizador na síntese de NPPs. Análises por MET indicaram NPPs de formato cúbico com diâmetros médios de 12,40 $\pm 3,27$ $\mathrm{nm}$ e carga de superfície de $35,5 \pm 3,7 \mathrm{mV}^{119}$. A biossíntese de NPPs foi realizada utilizando extrato aquoso da casca de Ficus racemosa (figueira), e sua atividade larvicida foi demonstrada contra larvas de Culex quinquefasciatus e Culex gelidus, importantes vetores de doenças ${ }^{120}$. NPPs foram sintetizadas utilizando extratos de Avicennia marina de diferentes partes da planta (folhas, cascas e raízes), sendo demonstrada que a menor taxa de formação ocorreu na presença de extrato da casca. As NPMs sintetizadas promoveram a inibição de crescimento de Escherichia coli e Staphylococcus aureus ${ }^{121}$. A avaliação do extrato de casca de Cinnamon zeylanicum para a síntese de NPMs resultou em NPPs cúbicas e hexagonais com tamanho variando entre $31 \mathrm{~nm}$ a $40 \mathrm{~nm}$, com atividade bactericida ${ }^{122}$. NPPs biossintetizadas utilizando extratos da casca do caule de Boswellia foram avaliados contra micro-organismos patogênicos dos gêneros Proteus, Pseudomonas, Klebsiella, 
Bacillus, E. coli, Aspergillus, Fusarium, Curvularia e Rhizopus, indicando que essas NPMs possuem eficácia alta contra diferentes micro-organismos ${ }^{123}$.

\subsubsection{Sementes}

Vijayaraghavana e colaboradores ${ }^{134}$ compararam a eficiência de extratos obtidos a partir da semente de Trachyspermum ammi (ajowan) e Papaver somniferum (papoula-do-oriente) na formação de nanopartículas de prata. Utilizando a mesma concentração de ambos os extratos, T. ammi formou partículas com formato triangular com diâmetro médio variando entre 87 $\mathrm{nm}$ e $998 \mathrm{~nm}$, enquanto $P$. somniferum resultou em partículas micrométricas esféricas com tamanho entre $3,2 \mu \mathrm{m}$ e $7,6 \mu \mathrm{m}^{124}$.

Concentrações variadas de extrato aquoso de sementes de Medicago sativa (alfafa) foram utilizadas como agente redutor para síntese de nanopartículas de prata. A maior e a menor concentrações utilizadas levaram à formação de NPMs de formatos esféricos e diâmetros variando de $5 \mathrm{~nm}$ a 51 $\mathrm{nm}$ e NPMs de formatos hexagonais e triangulares com comprimentos das arestas de $86 \mathrm{~nm}$ a $108 \mathrm{~nm}$, respectivamente. Adicionalmente, os tamanhos e formas das NPMs também foram modulados variando a concentração do íon metálico e do $\mathrm{pH}$ do meio reacional ${ }^{125}$.

O extrato de sementes de Cuminum cyminum (cominho) foi utilizado na biossíntese de NPOs. Os efeitos da temperatura e do $\mathrm{pH}$ foram avaliados, demonstrando que, quando a reação é submetida a temperaturas mais altas, são formadas NPMs de formato esférico e tamanho monodisperso entre 1 $\mathrm{nm}$ e $10 \mathrm{~nm}^{126}$.

\subsubsection{Outras partes das plantas}

O potencial redutor e estabilizante de extratos obtidos a partir de flores também tem sido explorado para a síntese de NPMs. O extrato aquoso de flores de Helianthus annuus (girassol) foi utilizado na síntese de NPOs. Análises por microscopia eletrônica de transmissão apresentaram NPOs polidispersas que variaram de $30 \mathrm{~nm}$ a $50 \mathrm{~nm}$, as quais apresentaram atividade antimicrobiana ${ }^{127}$. Outro estudo explorou o potencial redutor e estabilizante de extrato etanólico de flores de Nyctanthes arbortristis na síntese de NPOs, obtendo partículas esféricas com diâmetro médio seco de $19,8 \pm 5,0 \mathrm{~nm}^{128}$. 
NPPs esféricas com $4 \mathrm{~nm}$ e dispersão uniforme foram obtidas a partir da goma de Anacardium occidentale L. (caju), apresentando atividade contra bactérias gram-negativas ${ }^{129}$. Adicionalmente, já foi demonstrado que água de coco obtida a partir de frutos de Cocos nucifera L., pode ser agente redutor na síntese de NPOs, formando partículas esféricas com diâmetro médio seco de $10,5 \pm 5 \mathrm{~nm}$, as quais não apresentaram citotoxicidade a linhagens celulares de câncer cervical humano (HeLa) e câncer de mama humano (MCF7) ${ }^{130}$. Sendo assim, a utilização de outros tecidos e fluidos vegetais, como por exemplo, seivas brutas e elaboradas, podem ser boas alternativas.

\subsection{SÍNTESE VERDE DE NANOPARTÍCULAS METÁLICAS POR OUTROS ORGANISMOS/CÉLULAS/VÍRUS}

Os animais também podem ser considerados como uma fonte promissora para a síntese de NPMs. Entretanto, apesar do potencial de oxirredução bem descrito para inúmeros tecidos, a sua utilização em rotas de síntese verde de NPMs é escassa quando comparada à utilização de plantas, bactérias ou outros organismos. O cultivo de células não tumorais (células embrionárias de rim - HEK-293) e tumorais (HeLa e células epiteliais malignas do colo do útero - $\mathrm{SiHa}$ ) resultaram na síntese de $\mathrm{NPOs}^{9,144}$.

Os vírus podem ser modelos de nucleação e montagem de materiais inorgânicos ${ }^{12}$, como candidatos em potencial para a síntese de NPMs. O vírus do mosaico do feijão foi utilizado como agente de nucleação na mineralização de materiais ${ }^{145}$. O vírus do mosaico do tabaco é constituído por subunidades proteicas que atuam na formação de nanotubos ${ }^{146}$. Adicionalmente, o vírus do mosaico do tabaco foi utilizado com sucesso na mineralização de nanofios cristalinos de sulfeto de chumbo (PbS), por meio de peptídeos exibidos na superfície dos bacteriófagos ${ }^{147}$.

A aplicação de micro-organismos, incluindo as bactérias e os fungos, é realizada com sucesso na síntese verde. Assim, um estudo recente avaliou a potencialidade de síntese de NPMs por protozoários. Leishmania sp promoveu a síntese de NPPs e NPOs, com diâmetros variando de $10 \mathrm{~nm}$ a $100 \mathrm{~nm}$ e de $50 \mathrm{~nm}$ a $100 \mathrm{~nm}$, respectivamente ${ }^{148}$. 


\subsection{DIFERENCAS ENTRE OS ORGANISMOS UTILIZADOS PARA A SÍNTESE VERDE}

A síntese verde de NPMs utilizando micro-organismos é de produção escalonável, benigna ao meio ambiente e muitas vezes ideal para aplicações biomédicas por oferecer biocompatibilidade. Organismos em cultura apresentam ainda diversas vantagens adicionais sobre outros organismos em rotas de síntese verde. Esse fato está relacionado à facilidade de crescimento in vitro, multiplicação rápida, manuseio fácil e controle das condições experimentais, os quais acarretam em um aumento na reprodutibilidade na síntese das NPMs ${ }^{149}$. Porém, a produção por micro-organismos tem um custo financeiro muito mais alto do que a síntese mediada, por exemplo, a partir de extratos de plantas. Assim, o uso de plantas para promover a biossíntese de NPMs se caracteriza por ser um método mais rápido e de alta eficiência, especialmente quando metais nobres, como prata e ouro, são utilizados ${ }^{150}$. Adicionalmente, há a oportunidade de realizar a síntese em apenas um passo, além do fato de que a planta pode prover agentes estabilizantes que podem até mesmo atuar como bioativos ${ }^{151}$. Entretanto, um aspecto ainda desafiante da síntese verde com plantas é a homogeneidade na produção dos extratos e, consequentemente, a reprodutibilidade das NPMs sintetizadas.

\subsection{PROTOCOLO PRÁTICO DE SÍNTESE VERDE DE NANOPARTÍCULAS METÁLICAS}

A síntese verde de NPMs envolve o uso de íons metálicos, obtidos geralmente a partir de sais; e agentes redutores, que podem ser moléculas, tais como os carboidratos, as proteínas, os peptídeos, os aminoácidos, os ácidos nucleicos, os nucleotídeos, as vitaminas; ou os metabólitos secundários, como os flavanoides, os terpenoides, as saponinas ou os polifenois; ou ainda que possam ser obtidos de organismos biológicos.

Embora não exista uma descrição única para todos os mecanismos envolvidos no crescimento de NPMs, pode-se postular um modelo que contemple as etapas envolvidas na formação das partículas independente do agente redutor envolvido na etapa de síntese. Sendo que as principais etapas consistem em: (1) redução de um sal metálico, por um agente redutor, formando átomos metálicos neutros; (2) os átomos metálicos neutros colidem uns com os outros, formando um núcleo estável, seguido pelo crescimento das NPMs pelo esgotamento dos íons metálicos livres; (3) processo de estabilização 
das NPMs realizada pela molécula redutora ou outras moléculas presentes no meio reacional, que estabilizam as partículas formadas, impedindo a aglomeração.

Os protocolos apresentados a seguir fazem parte do acervo de protocolos desenvolvidos ou adaptados pelos pesquisadores, estudantes e colaboradores do Grupo de Nanotecnologia e Biologia Sintética, Embrapa Recursos Genéticos e Biotecnologia.

\section{Materiais para síntese verde de nanopartículas metálicas}

- Material biológico (biomoléculas, células, tecidos, órgãos ou seus respectivos extratos, exsudatos ou sobrenadantes)

- Meios de cultura (células eucarióticas e procarióticas)

- Cloretos metálicos (alumínio, bário, cádmio, cálcio, cobalto, cobre, cromo, estrôncio, ferro, lítio, magnésio, manganês, mercúrio, níquel, ouro, paládio, potássio, prata, platina, sódio, zinco, entre outros)

- Nitratos metálicos (alumínio, bário, bismuto, cádmio, cálcio, cério, chumbo, cobalto, cobre, cromo, estrôncio, ferro, lantânio, lítio, magnésio, manganês, mercúrio, níquel, potássio, prata, sódio, tório, uranila, zinco, entre outros)

- Acetatos metálicos (alumínio, bário, cádmio, cálcio, chumbo, cobre, magnésio, mercúrio, sódio, zinco, entre outros)

- Sulfatos metálicos (alumínio, bário, cádmio, cálcio, cério, cobre, ferro, lítio, magnésio, manganês, mercúrio, níquel, potássio, prata, sódio, zinco)

- Carbonatos de metálicos (bário, bismuto, cálcio, chumbo, cobre, estrôncio, lítio, potássio, sódio, entre outros)

- Citratos metálicos (ferro, potássio, sódio, entre outros)

- Fosfatos metálicos (potássio, sódio, cálcio, entre outros)

- Microplacas de 96 e 384 poços de fundo chato para leitoras de microplacas

- Vidrarias (béqueres, Erlenmeyers, balões de fundo chato, tubo de ensaio, funil, bastão de vidro)

- Papel-alumínio

- Cubetas plásticas para espectrofotometria

- Tubos tipo Falcon ou microtubos $(0,6 \mathrm{~mL}, 1,5 \mathrm{~mL}, 2,0 \mathrm{~mL}, 15 \mathrm{~mL}$ e $50 \mathrm{~mL}$ )

- Água destilada e ultrapura

- Membranas filtrantes 
- Micropipetas $(2 \mu \mathrm{L}, 20 \mu \mathrm{L}, 100 \mu \mathrm{L}, 1.000 \mu \mathrm{L}, 5.000 \mu \mathrm{L}$ e $10.000 \mu \mathrm{L})$

- Ponteiras para micropipetas

Equipamentos para síntese verde de nanopartículas metálicas

- Estufa

- Banho-maria

- Leitora de microplacas ou espectrofotômetro com comprimentos de onda variáveis no UV/Vis para monitoramento da formação de nanopartículas

- Capela com fluxo laminar (cabine de segurança biológica)

- Centrífuga

- Agitador tipo shaker orbital de bancada com aquecimento

- Geladeira

- Freezer $-20{ }^{\circ} \mathrm{C}$ vertical/horizontal

- pHmetro

\section{Métodos}

Os métodos que seguem podem ser adaptados para rotas de síntese verde com outros agentes redutores (moléculas, extratos ou células) ou íons metálicos. Para fins de clareza e simplicidade das metodologias apresentadas, os métodos escolhidos foram baseados no uso de nitrato de prata como sal metálico e leveduras, bactérias, células de mamíferos, aminoácidos ou extratos de plantas como agentes redutores.

\section{Células}

Bactérias e leveduras são cultivadas em meio apropriado para cada linhagem celular durante 24 horas a $28{ }^{\circ} \mathrm{C}$ em agitador rotativo $(120 \mathrm{rpm})$. O meio de cultura contendo as células é centrifugado a $120 \mathrm{~g}$ e todo o sobrenadante é descartado, restando apenas as células, as quais são lavadas com água ultrapura para remover quaisquer componentes oriundos do meio de cultura. Para a síntese das NPMs, $10^{5}$ a $10^{7}$ células são adicionadas a $100 \mathrm{~mL}$ a $1 \mathrm{~mL}$ de nitrato de prata $1 \mathrm{mM}$ e incubadas a $28{ }^{\circ} \mathrm{C}$ durante 24 horas, sendo todas as soluções mantidas no escuro para evitar reações fotoquímicas. Após esse período, a solução é submetida à centrifugação $120 \mathrm{~g}$ a $4{ }^{\circ} \mathrm{C}$ por 10 minutos, e o sobrenadante contendo as partículas é recolhido. Adicionalmente, o sobrenadante de um lisado das células submetidas à 
ultrassonicação por alguns minutos (10 a 30) pode ser escolhido como componente biorredutor em vez do uso das células. Pequenas variações podem ser aplicadas nos protocolos para utilização de células de mamíferos.

\section{Tecidos vegetais}

Os tecidos vegetais ( $10 \mathrm{~g}$ a $15 \mathrm{~g}$ ) são coletados e armazenados em freezer $\left(-20^{\circ} \mathrm{C}\right)$ até o momento do uso, quando são lavados com detergente Dex$\operatorname{tran}^{\circledR}$ diluído $2.000 \times$ em água destilada durante 3 minutos, seguido por três ciclos de enxágue em água destilada. Os tecidos são cortados em pequenos pedaços $(\sim 3 \mathrm{~mm}$ ) com o auxílio de aparato cortante (tesoura ou triturador) e fervidos em $150 \mathrm{~mL}$ de água ultrapura por 3 minutos. O extrato é submetido à filtração por gravidade, com papel de filtro Whatman $n^{\circ} 1$, para remover os resíduos de folha, ao abrigo da luz ambiente. O extrato aquoso é imediatamente utilizado para a síntese das NPMs. Para a síntese das NPMs, $50 \mu \mathrm{L}$ do extrato aquoso filtrado são adicionados a $4.950 \mu \mathrm{L}$ de solução de nitrato de prata $\left(\mathrm{AgNO}_{3}\right) 1 \mathrm{mM}$. As reações entre os componentes do extrato e os íons $\mathrm{Ag}^{+}$para $\mathrm{Ag}^{0}$ são realizadas em béquer de vidro, no escuro, durante 3 a 24 horas em banho-maria de $25^{\circ} \mathrm{C}$ a $75^{\circ} \mathrm{C}$.

\section{Biomoléculas}

Soluções de biomoléculas ou de suas unidades fundamentais (por exemplo, aminoácidos) também são utilizadas na síntese de NPMs. A síntese ocorre adicionando $100 \mu \mathrm{L}$ de solução de aminoácido $(2 \mathrm{mM}$ a $20 \mathrm{mM}$ ) a $100 \mu \mathrm{L}$ solução de nitrato de prata $\left(\mathrm{AgNO}_{3}\right) 2 \mathrm{mM}$. As reações entre o aminoácido (ou alguma outra biomolécula) e os íons $\mathrm{Ag}^{+}$para conversão a $\mathrm{Ag}^{0}$ são realizadas em tubos ou microplacas de polipropileno, protegidas da luz, durante 24 a 72 horas para ocorrer a biorredução. Diversos aminoácidos podem ser utilizados: glicina, alanina, serina, prolina, valina, treonina, cisteína, leucina, isoleucina, asparagina, aspartato, lisina, glutamina, glutamato, metionina, histidina, fenilalanina, arginina, tirosina ou triptofano; assim como qualquer biomolécula hidrossolúvel pode ser avaliada quanto ao potencial de biorredução de íons metálicos.

Considerações gerais e métodos de caracterização das NPMs

As concentrações de agentes redutores e metal podem ser variados de acordo com a fonte biológica, por exemplo, células, biomassa, espécies e 
parte de plantas, locais de coleta, sazonalidade, biomoléculas e metabólitos; bem como do íon metálico utilizado $\left(\mathrm{Ag}^{+}, \mathrm{Li}^{+}, \mathrm{Na}^{+}, \mathrm{K}^{+}, \mathrm{Rb}^{+}, \mathrm{Cs}^{+}, \mathrm{Mg}^{2+}, \mathrm{Ca}^{2+}\right.$, $\mathrm{Sr}^{2+}, \mathrm{Ba}^{2+}, \mathrm{Ni}^{2+}, \mathrm{Co}^{2+}, \mathrm{Fe}^{2+}, \mathrm{Mn}^{2+}, \mathrm{Zn}^{2+}, \mathrm{Cd}^{2+}, \mathrm{Pb}^{2+}, \mathrm{Cu}^{2+}, \mathrm{Fe}^{3+}$; os quais podem ser oriundos de cloretos, nitratos, acetatos, sulfatos, citratos, carbonatos, entre outras formas). Além disso, as reações podem ser realizadas variando-se o tempo, temperatura ou $\mathrm{pH}$ de reação, assim como o tamanho dos constituintes da amostra quando esta é previamente submetida a membranas filtrantes. Todas essas variações são realizadas no intuito de controlar a taxa de formação ou o tamanho/forma das NPMs. Da mesma forma, são possíveis escalonamentos dos volumes de alguns poucos microlitros até centenas de mililitros ou até mesmo litros. O armazenamento das NPMs é realizado preferencialmente a $4{ }^{\circ} \mathrm{C}$.

As NPMs sintetizadas podem ser caracterizadas quanto aos efeitos cinéticos de formação monitorados espectrofotometricamente; $\mathrm{pH}$; tamanho e forma secos (MFA, MET e MEV); índice de polidispersividade (PdI); potencial Zeta de superfície (microeletroforético) e diâmetro hidrodinâmico (espalhamento de luz dinâmico); condutividade elétrica (condutivímetro); estrutura cristalina (difração de raio X); composição elementar (espectroscopia de energia dispersiva); composição química (FTIR, cromatografia líquida de alta eficiência, espectrometria de massa, ressonância nuclear magnética); atividade biológica (como viabilidade celular e hemólise); entre outras abordagens.

\subsection{POSSIBILIDADES TERAPÊUTICAS E AGROINDUSTRIAIS DE NANOPARTÍCULAS METÁLICAS}

As características dos materiais nanométricos podem impactar diversas áreas e também setores industriais, como químico, farmacêutico, alimentos, agricultura, têxtil, energia, dentre outros. As aplicações de NPMs dependem do tipo de rota de síntese escolhida e principalmente da partícula produzida. Nos últimos anos as NPMs, produzidas por meio de rotas de síntese verde, propulsionam diversos setores no que tange a estratégias de pesquisa, desenvolvimento e inovação com sustentabilidade.

As aplicações das NPMs proporcionam um impacto significativo para a sociedade contemporânea nas áreas de separação magnética e concentração de materiais de interesse; sistemas eletrônicos de armazenamento; sistemas de liberação de moléculas; sensores; embalagens funcionais; têxteis; materiais esportivos, dentre outros. As NPPs, por exemplo, por apresentar ação 
antimicrobiana, são utilizadas em embalagens, produtos de uso hospitalar e até mesmo em tecidos. Em geral, NPMs utilizadas no campo de biotecnologia variam em diâmetro entre $5 \mathrm{~nm}$ a $500 \mathrm{~nm}$, enquanto aquelas mais utilizadas em aplicações biomédicas variam em diâmetro de $5 \mathrm{~nm}$ a $20 \mathrm{~nm}$. As NPMs obtidas por meio de rotas de síntese verde satisfazem essas condições, além de apresentar revestimentos moleculares como agentes estabilizantes ou poder até mesmo ser conjugadas com outras moléculas biológicas que confiram biocompatibilidade e seletividade e possam ser utilizadas em aplicações biológicas e biomédicas (Tabela 26.5).

$\mathrm{Na}$ área da saúde pública, o controle de vetores/patógenos que causam danos à saúde humana é uma necessidade importante. Nesse caso, o uso de NPMs sintetizadas via nanotecnologia verde demonstram um grande potencial para o controle de organismos tais como Culex quinquefasciatus, Culex gelidus, Leishmania sp, Staphylococcus aureus, Escherichia coli e Pseudomonas aeruginosa $a^{80,120,148}$. Além disso, o diagnóstico de doenças também pode ser contemplado pelo uso das NPMs como pontos quânticos ou nanobiossensores para detecção de células tumorais, entre outros ${ }^{7} . \mathrm{Na}$ área ambiental, a estratégia de nanobiorremediação é essencial para a recuperação de regiões comprometidas pela presença de contaminantes. Nesse caso, algas, fungos e plantas são importantes exemplos para esse emprego das NPMs ${ }^{9}$. Outros setores industriais, como por exemplo, o têxtil, também podem utilizar as NPMs para melhorar a qualidade ou adicionar novas propriedades (tecidos superabsorventes ou super-repelentes com propriedades distintas, incluindo a ação antibacteriana $)^{5}$.

Tabela 26.5 Atividades biotecnológicas e biomédicas de nanopartículas metálicas obtidas por rotas de síntese verde

\begin{tabular}{ccc}
\hline NANOPARTícULA & ATIVIDADE & REFERÊNCIAS \\
Prata & Acaricida & 4 \\
\hline Prata & Antiangiogênica & 26 \\
\hline Prata & Anticâncer & 51 \\
\hline Prata & Anticoagulante & 55 \\
\hline Prata & Antifúngica & $76,95,123,155$ \\
\hline \multirow{2}{*}{ Prata } & Antimicrobiana & $11,27,31,47,50,64,65,79,80,81,95,112,113$, \\
& $121,122,123,129,132,138,139,143,152,157$ \\
\hline Prata & Antioxidante & 140 \\
\hline Prata & Antiparaśitica & 96 \\
\hline Prata & Larvicida & $120,153,154$ \\
\hline Ouro & Anticâncer & 156,158 \\
\hline
\end{tabular}




\begin{tabular}{ccc}
\hline NANOPARTÍCULA & ATIVIDADE & REFERÊNCIAS \\
\hline Ouro & Anticoagulante & 55 \\
\hline Ouro & Antimicrobiana & 69,127 \\
\hline Ouro & Biocatalisador & 56 \\
\hline Ouro & Biocompatibilidade & 130 \\
\hline Ouro & Biossensor de vapor & 142 \\
\hline Ouro e Prata & Diagnóstico in vitro & $7,159-161$ \\
\hline Titânio & Antibacteriana & 48 \\
\hline
\end{tabular}

\subsection{CONCLUSÃO E PERSPECTIVAS FUTURAS}

Nanopartículas têm despertado fascínio desde muito antes do advento da nanotecnologia, ocorrido há não muito mais do que 20 a 30 anos. De fato, pigmentos utilizados há milhares de anos em grafismos rupestres foram elaborados à base de óxidos de ferro misturados a extratos ou óleos/gorduras de origem animal e vegetal, os quais em suma poderiam ser denominados atualmente de rotas de síntese verde de NPMs. Nesse contexto, o reconhecimento de que os organismos biológicos, sejam eles procariontes ou eucariontes, são importantes fontes biológicas que podem contribuir para a inovação biotecnológica via nanotecnologia verde, não é um fenômeno recente, mas sim uma reinovação tecnológica com repercussões ainda imprevisíveis.

Apesar de relatos científicos sobre os diversos tipos de nanopartículas serem bastante recentes, esta é uma área da nanotecnologia que vem experimentando crescente evolução (Figura 26.3). Após observação dos relatos encontrados na literatura científica e tecnológica sobre síntese verde, é evidente que os organismos biológicos estão sendo explorados com sucesso para a síntese de nanopartículas a partir de metais, de forma rápida e a taxas comparáveis às sínteses com compostos químicos clássicos. Porém, um desafio atual e essencial é de que o mecanismo de redução e estabilização para cada nova rota de síntese seja conhecido e caracterizado, no intuito de aperfeiçoar a reação de síntese e também minimizar o empirismo atual na escolha de novos componentes biológicos como agentes redutores. Além disso, uma preocupação e desafio atuais é a elaboração das rotas para a degradação ou dissolução das NPMs formadas, em uma área que busca a 


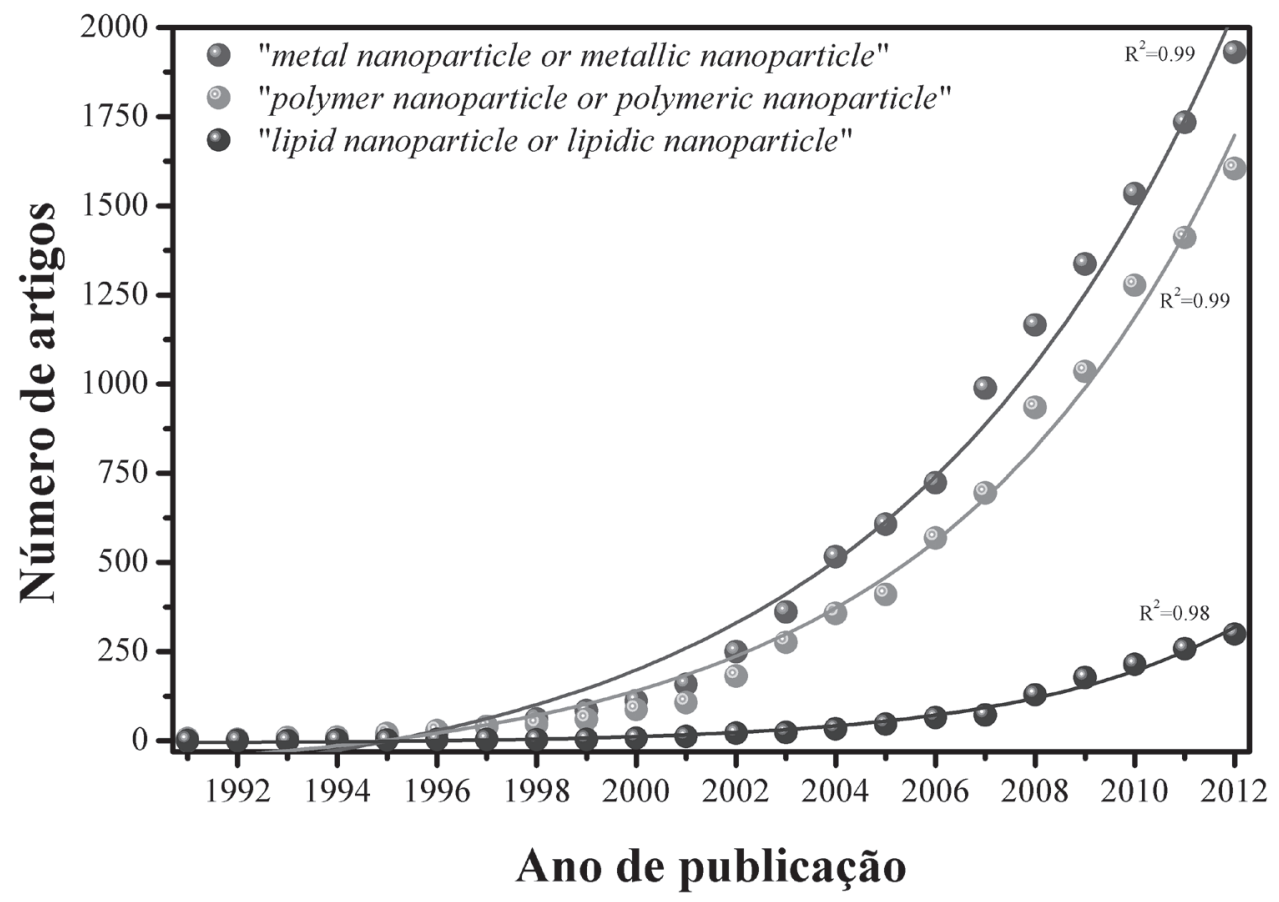

Figura 26.3 Número de artigos publicados sobre os diferentes tipos de nanopartículas (metálicas, poliméricas ou lipídicas), de acordo com a base de dados do ISI Web of Science. Os termos de busca foram utilizados em língua inglesa.

mitigação dos potenciais riscos associados a essa tecnologia, de modo que se possa rotular a nanotecnologia verde como sustentável. 


\section{REFERÊNCIAS}

1. Zhang L, Pornpattananangkul D, Hu CMJ, Huang CM. Development of Nanoparticles for Antimicrobial Drug Delivery. Current Medicinal Chemistry. 2010;17(6):585-94.

2. Rai M, Ingle A. Role of nanotechnology in agriculture with special reference to management of insect pests. Applied Microbiology and Biotechnology. 2012;94(2):287-93.

3. Jabir NR, Tabrez S, Ashraf GM, Shakil S, Damanhouri GA, Kamal MA. Nanotechnology-based approaches in anticancer research. International Journal of Nanomedicine. 2012;7:4391-408.

4. Jayaseelan C, Rahuman AA. Acaricidal efficacy of synthesized silver nanoparticles using aqueous leaf extract of Ocimum canum against Hyalomma anatolicum and Hyalomma marginatum isaaci (Acari: Ixodidae). Parasitology Research. 2012;111(3):1369-78.

5. Fahmy TYA, Mobarak F. Green nanotechnology: A short cut to beneficiation of natural fibers. International Journal of Biological Macromolecules. 2011;48(1):134-6.

6. Nath D, Banerjee P. Green nanotechnology - A new hope for medical biology. Environmental Toxicology and Pharmacology. 2013;36(3):997-1014.

7. Mittal AK, Bhaumik J, Kumar S, Banerjee UC. Biosynthesis of silver nanoparticles: Elucidation of prospective mechanism and therapeutic potential. Journal of Colloid and Interface Science. 2014;415(0):39-47.

8. Zhang YX, Zheng J, Gao G, Kong YF, Zhi X, Wang K, Zhang XQ, Cui DX. Biosynthesis of gold nanoparticles using chloroplasts. International Journal of Nanomedicine. 2011;6:2899-906.

9. Narayanan KB, Sakthivel N. Green synthesis of biogenic metal nanoparticles by terrestrial and aquatic phototrophic and heterotrophic eukaryotes and biocompatible agents. Advances in Colloid and Interface. Science. 2011;169(2):59-79.

10. Shukla VK, Yadav RS, Yadav P, Pandey AC. Green synthesis of nanosilver as a sensor for detection of hydrogen peroxide in water. Journal of Hazardous Materials. 2012;213:161-6.

11. Sharma VK, Yngard RA, Lin Y. Silver nanoparticles: Green synthesis and their antimicrobial activities. Advances in Colloid and Interface Science. 2009;145(1-2):83-96. 12. Thakkar KN, Mhatre SS, Parikh RY. Biological synthesis of metallic nanoparticles. Nanomedicine-Nanotechnology Biology and Medicine. 2010;6(2):257-62.

13. Mittal AK, Chisti Y, Banerjee UC. Synthesis of metallic nanoparticles using plant extracts. Biotechnology Advances. 2013;31(2):346-56.

14. Faramarzi MA, Sadighi A. Insights into biogenic and chemical production of inorganic nanomaterials and nanostructures. Advances in Colloid and Interface Science. 2013;189:1-20. 
15. Lloyd JR, Byrne JM, Coker VS. Biotechnological synthesis of functional nanomaterials. Current Opinion in Biotechnology. 2011;22(4):509-15.

16. Sinha S, Pan I, Chanda P, Sen SK. Nanoparticles fabrication using ambient biological resources. Journal of Applied Biosciences. 2009;19:1113-30.

17. Gericke M, Pinches A. Biological synthesis of metal nanoparticles. Hydrometallurgy. 2006;83(1-4):132-40.

18. Philip D. Biosynthesis of Au, Ag and Au-Ag nanoparticles using edible mushroom extract. Spectrochimica Acta Part A: Molecular and Biomolecular Spectroscopy. 2009;73(2):374-81.

19. Chauhan A, Zubair S, Tufail S, Sherwani A, Sajid M, Raman SC, Azam A, Owais M. Fungus-mediated biological synthesis of gold nanoparticles: potential in detection of liver cancer. International Journal of Nanomedicine. 2011;6:2305-19.

20. Baker S, Rakshith D, Kavitha KS, Santosh P, Kavitha HU, Rao Y, Satish S. Plants: Emerging as Nanofactories towards Facile Route in Synthesis of Nanoparticles. Bioimpacts. 2013;3(3):111-7.

21. Mata YN, Torres E, Blazquez ML, Ballester A, Gonzalez F, Munoz JA. Gold(III) biosorption and bioreduction with the brown alga Fucus vesiculosus. Journal of Hazardous Materials. 2009;166(2-3):612-8.

22. Nadkarni VD, Pervin A, Linhardt RJ. Directional immobilization of heparin onto beaded supports. Analytical Biochemistry. 1994;222(1):59-67.

23. Kemp MM, Kumar A, Mousa S, Park T-J, Ajayan P, Kubotera N, Mousa SA, Linhardt RJ. Synthesis of Gold and Silver Nanoparticles Stabilized with Glycosaminoglycans Having Distinctive Biological Activities. Biomacromolecules. 2009;10(3):589-95.

24. Park Y, Hong YN, Weyers A, Kim YS, Linhardt RJ. Polysaccharides and phytochemicals: a natural reservoir for the green synthesis of gold and silver nanoparticles. Iet Nanobiotechnology. 2011;5(3):69-78.

25. Doughty MJ, Glavin S. Efficacy of different dry eye treatments with artificial tears or ocular lubricants: a systematic review. Ophthalmic and Physiological Optics. 2009;29(6):573-83.

26. Kemp MM, Kumar A, Mousa S, Dyskin E, Yalcin M, Ajayan P, Linhardt RJ, Mousa SA. Gold and silver nanoparticles conjugated with heparin derivative possess antiangiogenesis properties. Nanotechnology. 2009;20(45).

27. Kemp MM, Kumar A, Clement D, Ajayan P, Mousa S, Linhardt RJ. Hyaluronanand heparin-reduced silver nanoparticles with antimicrobial properties. Nanomedicine. 2009;4(4):421-9.

28. Huang HZ, Yang XR. Synthesis of polysaccharide-stabilized gold and silver nanoparticles: a green method. Carbohydrate Research. 2004;339(15):2627-31.

29. Onishi H, Machida Y. Biodegradation and distribution of water-soluble chitosan in mice. Biomaterials. 1999;20(2):175-82. 
30. Joshi JM, Sinha VK. Ceric ammonium nitrate induced grafting of polyacrylamide onto carboxymethyl chitosan. Carbohydrate Polymers. 2007;67(3):427-35.

31. Venkatesham M, Ayodhya D, Madhusudhan A, Babu NV, Veerabhadram G. A novel green one-step synthesis of silver nanoparticles using chitosan: catalytic activity and antimicrobial studies. Applied Nanoscience. 2012:1-7.

32. Goswami N, Saha R, Pal SK. Protein-assisted synthesis route of metal nanoparticles: exploration of key chemistry of the biomolecule. Journal of Nanoparticle Research. 2011;13(10):5485-95.

33. Tan YN, Lee JY, Wang DIC. Uncovering the Design Rules for Peptide Synthesis of Metal Nanoparticles. Journal of the American Chemical Society. 2010;132(16):5677-86. 34. Galloway JM, Staniland SS. Protein and peptide biotemplated metal and metal oxide nanoparticles and their patterning onto surfaces. Journal of Materials Chemistry. 2012;22(25):12423-34.

35. Shao Y, Jin YD, Dong SJ. Synthesis of gold nanoplates by aspartate reduction of gold chloride. Chemical Communications. 2004;(9):1104-5.

36. Daima HK, Selvakannan P, Bhargava SK, Bansal V. Threonine amino acid mediated photochemical synthesis of $\mathrm{Au}, \mathrm{Ag}$ and Bimetallic Au-Ag nanoparticles with antibacterial activity. Chemeca 2011: Engineering a Better World. Sydney, Australia; 2011. p. 365.

37. Ho J-aA, Chang H-C, Su W-T. DOPA-Mediated Reduction Allows the Facile Synthesis of Fluorescent Gold Nanoclusters for Use as Sensing Probes for Ferric Ions. Analytical Chemistry. 2012;84(7):3246-53.

38. Wang Z, Zhu H, Wang X, Yang F, Yang X. One-pot green synthesis of biocompatible arginine-stabilized magnetic nanoparticles. Nanotechnology. 2009;20(46).

39. Dickerson MB, Sandhage KH, Naik RR. Protein- and Peptide-Directed Syntheses of Inorganic Materials. Chemical Reviews. 2008;108(11):4935-78.

40. Berti L, Burley GA. Nucleic acid and nucleotide-mediated synthesis of inorganic nanoparticles. Nat Nanotechnol. 2008;3(2):81-7.

41. Yin Y, Alivisatos AP. Colloidal nanocrystal synthesis and the organic-inorganic interface. Nature. 2005;437(7059):664-70.

42. Wang Z, Zhang J, Ekman JM, Kenis PJA, Lu Y. DNA-Mediated Control of Metal Nanoparticle Shape: One-Pot Synthesis and Cellular Uptake of Highly Stable and Functional Gold Nanoflowers. Nano Letters. 2010;10(5):1886-91.

43. Gugliotti LA, Feldheim DL, Eaton BE. RNA-mediated metal-metal bond formation in the synthesis of hexagonal palladium nanoparticles. Science. 2004;304(5672):850-2. 44. Tyagi H, Kushwaha A, Kumar A, Aslam M. pH-dependent synthesis of stabilized gold nanoparticles using ascorbic acid. International Journal of Nanoscience. 2011;10(04n05):857-60. 
45. Nadagouda MN, Varma RS. Green and controlled synthesis of gold and platinum nanomaterials using vitamin B-2: density-assisted self-assembly of nanospheres, wires and rods. Green Chemistry. 2006;8(6):516-8.

46. Nadagouda MN, Varma RS. Green synthesis of Ag and Pd nanospheres, nanowires, and nanorods using vitamin $\mathrm{B}(2)$ : Catalytic polymerisation of aniline and pyrrole. Journal of Nanomaterials. 2008.

47. Zhou W, Zhang Y, Ding X, Liu Y, Shen F, Zhang X, Deng S, Xiao H, Yang G, Peng H. Magnetotactic bacteria: promising biosorbents for heavy metals. Applied Microbiology and Biotechnology. 2012;95(5):1097-104.

48. Cai F, Li J, Sun J, Ji Y. Biosynthesis of gold nanoparticles by biosorption using Magnetospirillum gryphiswaldense MSR-1. Chemical Engineering Journal. 2011;175:70-5.

49. Tanaka M, Arakaki A, Staniland SS, Matsunaga T. Simultaneously Discrete Biomineralization of Magnetite and Tellurium Nanocrystals in Magnetotactic Bacteria. Applied and Environmental Microbiology. 2010;76(16):5526-32.

50. Singh R, Wagh P, Wadhwani S, Gaidhani S, Kumbhar A, Bellare J, Chopade BA. Synthesis, optimization, and characterization of silver nanoparticles from Acinetobacter calcoaceticus and their enhanced antibacterial activity when combined with antibiotics. International Journal of Nanomedicine. 2013;8:4277-89.

51. Jayaseelan C, Rahuman AA, Roopan SM, Kirthi AV, Venkatesan J, Kim S-K, Iyappan M, Siva C. Biological approach to synthesize TiO2 nanoparticles using Aeromonas hydrophila and its antibacterial activity. Spectrochimica Acta Part A: Molecular and Biomolecular Spectroscopy. 2013;107:82-9.

52. Brayner R, Yepremian C, Djediat C, Coradin T, Herbst F, Livage J, Fievet F, Coute A. Photosynthetic Microorganism-Mediated Synthesis of Akaganeite (beta-FeOOH) Nanorods. Langmuir. 2009;25(17):10062-7.

53. Wei X, Luo M, Li W, Yang L, Liang X, Xu L, Kong P, Liu H. Synthesis of silver nanoparticles by solar irradiation of cell-free Bacillus amyloliquefaciens extracts and AgNO3. Bioresource Technology. 2012;103(1):273-8.

54. Gurunathan S, Han JW, Eppakayala V, Jeyaraj M, Kim J-H. Cytotoxicity of Biologically Synthesized Silver Nanoparticles in MDA-MB-231 Human Breast Cancer Cells. Biomed Research International. 2013.

55. Pugazhenthiran N, Anandan S, Kathiravan G, Prakash NKU, Crawford S, Ashokkumar M. Microbial synthesis of silver nanoparticles by Bacillus sp. Journal of Nanoparticle Research. 2009;11(7):1811-5.

56. Zhang H, Yu X, Guo D, Qu B, Zhang M, Li Q, Wang T. Synthesis of Bacteria Promoted Reduced Graphene Oxide-Nickel Sulfide Networks for Advanced Supercapacitors. Acs Applied Materials \& Interfaces. 2013;5(15):7335-40. 
57. Pandian SRK, Deepak V, Kalishwaralal K, Gurunathan S. Biologically synthesized fluorescent CdS NPs encapsulated by PHB. Enzyme and Microbial Technology. 2011;48(4-5):319-25.

58. Kalishwaralal K, Deepak V, Pandian SRK, Kottaisamy M, BarathManiKanth S, Kartikeyan B, Gurunathan S. Biosynthesis of silver and gold nanoparticles using Brevibacterium casei. Colloids and Surfaces B: Biointerfaces. 2010;77(2):257-62.

59. Srivastava SK, Yamada R, Ogino C, Kondo A. Biogenic synthesis and characterization of gold nanoparticles by Escherichia coli K12 and its heterogeneous catalysis in degradation of 4-nitrophenol. Nanoscale Research Letters. 2013;8.

60. Monras JP, Diaz V, Bravo D, Montes RA, Chasteen TG, Osorio-Roman IO, Vasquez CC, Perez-Donoso JM. Enhanced Glutathione Content Allows the In Vivo Synthesis of Fluorescent CdTe Nanoparticles by Escherichia coli. Plos One. 2012;7(11).

61. Correa-Llanten DN, Munoz-Ibacache SA, Castro ME, Munoz PA, Blamey JM. Gold nanoparticles synthesized by Geobacillus sp strain ID17 a thermophilic bacterium isolated from Deception Island, Antarctica. Microbial Cell Factories. 2013;12.

62. Tuo Y, Liu G, Zhou J, Wang A, Wang J, Jin R, Lv H. Microbial formation of palladium nanoparticles by Geobacter sulfurreducens for chromate reduction. Bioresource Technology. 2013;133:606-11.

63. Srivastava S, Constanti M. Room temperature biogenic synthesis of multiple nanoparticles (Ag, Pd, Fe, Rh, Ni, Ru, Pt, Co, and Li) by Pseudomonas aeruginosa SM1. Journal of Nanoparticle Research. 2012;14(4):1-10.

64. Varshney R, Bhadauria S, Gaur MS, Pasricha R. Characterization of Copper Nanoparticles Synthesized by a Novel Microbiological Method. Jom. 2010;62(12):102-4. 65. Oves M, Khan MS, Zaidi A, Ahmed AS, Ahmed F, Ahmad E, Sherwani A, Owais M, Azam A. Antibacterial and Cytotoxic Efficacy of Extracellular Silver Nanoparticles Biofabricated from Chromium Reducing Novel OS4 Strain of Stenotrophomonas maltophilia. Plos One. 2013;8(3).

66. Prakasham RS, Kumar BS, Kumar YS, Shankar GG. Characterization of Silver Nanoparticles Synthesized by Using Marine Isolate Streptomyces albidoflavus. Journal of Microbiology and Biotechnology. 2012;22(5):614-21.

67. Manikprabhu D, Lingappa K. Microwave Assisted Rapid and Green Synthesis of Silver Nanoparticles Using a Pigment Produced by Streptomyces coelicolor klmp33. Bioinorganic Chemistry and Applications. 2013.

68. Deplanche K, Macaskie LE. Biorecovery of gold by Escherichia coli and Desulfovibrio desulfuricans. Biotechnology and Bioengineering. 2008;99(5):1055-64.

69. Sawosz E, Chwalibog A, Szeliga J, Sawosz F, Grodzik M, Rupiewicz M, Niemiec T, Kacprzyk K. Visualization of gold and platinum nanoparticles interacting with Salmonella enteritidis and Listeria monocytogenes. International Journal of Nanomedicine. 2010;5:631-7. 
70. Asmathunisha N, Kathiresan K. A review on biosynthesis of nanoparticles by marine organisms. Colloids and Surfaces B: Biointerfaces. 2013;103:283-7.

71. Stengel DB, Connan S, Popper ZA. Algal chemodiversity and bioactivity: Sources of natural variability and implications for commercial application. Biotechnology Advances. 2011;29(5):483-501.

72. Barwal I, Ranjan P, Kateriya S, Yadav SC. Cellular oxido-reductive proteins of Chlamydomonas reinhardtii control the biosynthesis of silver nanoparticles. Journal of Nanobiotechnology. 2011;9.

73. Mohseniazar M, Barin M, Zarredar H, Alizadeh S, Shanehbandi D. Potential of microalgae and lactobacilli in biosynthesis of silver nanoparticles. Bioimpacts. 2011;1(3):149-52.

74. Lirdprapamongkol K, Warisnoicharoen W, Soisuwan S, Svasti J. Eco-friendly synthesis of fucoidan-stabilized gold nanoparticles. American Journal of Applied Sciences. 2010;7(8):1038.

75. Schroefel A, Kratosova G, Bohunicka M, Dobrocka E, Vavra I. Biosynthesis of gold nanoparticles using diatoms-silica-gold and EPS-gold bionanocomposite formation. Journal of Nanoparticle Research. 2011;13(8):3207-16.

76. Vivek M, Kumar PS, Steffi S, Sudha S. Biogenic silver nanoparticles by Gelidiella acerosa extract and their antifungal effects. Avicenna Journal of Medical Biotechnology. $2011 ; 3(3): 143$.

77. Singaravelu G, Arockiamary JS, Kumar VG, Govindaraju K. A novel extracellular synthesis of monodisperse gold nanoparticles using marine alga, Sargassum wightii Greville. Colloids and Surfaces B: Biointerfaces. 2007;57(1):97-101.

78. Mahdavi M, Namvar F, Ahmad M, Mohamad R. Green Biosynthesis and Characterization of Magnetic Iron Oxide (Fe3O4) Nanoparticles Using Seaweed (Sargassum muticum) Aqueous Extract. Molecules. 2013;18(5):5954-64.

79. Rajesh S, Raja DP, Rathi J, Sahayaraj K. Biosynthesis of silver nanoparticles using Ulva fasciata (Delile) ethyl acetate extract and its activity against Xanthomonas campestris pv. malvacearum. Journal of Biopesticides. 2012;5(119):2012.

80. Govindaraju K, Kiruthiga V, Kumar VG, Singaravelu G. Extracellular Synthesis of Silver Nanoparticles by a Marine Alga, Sargassum Wightii Grevilli and Their Antibacterial Effects. Journal of Nanoscience and Nanotechnology. 2009;9(9):5497-501. 81. El-Rafie HM, El-Rafie MH, Zahran MK. Green synthesis of silver nanoparticles using polysaccharides extracted from marine macro algae. Carbohydrate Polymers. 2013;96(2):403-10.

82. Kaminskyj S, Jilkine K, Szeghalmi A, Gough K. High spatial resolution analysis of fungal cell biochemistry - bridging the analytical gap using synchrotron FTIR spectromicroscopy. FEMS Microbiol Lett. 2008;284(1):1-8. 
83. Kowshik M, Deshmukh N, Vogel W, Urban J, Kulkarni S, Paknikar K. Microbial synthesis of semiconductor CdS nanoparticles, their characterization, and their use in the fabrication of an ideal diode. Biotechnology and Bioengineering. 2002;78(5):583-8. 84. Ahmad A, Mukherjee P, Senapati S, Mandal D, Khan MI, Kumar R, Sastry M. Extracellular biosynthesis of silver nanoparticles using the fungus Fusarium oxysporum. Colloids and Surfaces B: Biointerfaces. 2003;28(4):313-8.

85. Bhainsa KC, D’Souza SF. Extracellular biosynthesis of silver nanoparticles using the fungus Aspergillus fumigatus. Colloids and Surfaces B: Biointerfaces. 2006;47(2):160-4. 86. Kashyap PL, Kumar S, Srivastava AK, Sharma AK. Myconanotechnology in agriculture: a perspective. World Journal of Microbiology \& Biotechnology. 2013;29(2):191-207.

87. Dameron C, Reese R, Mehra R, Kortan A, Carroll P, Steigerwald M, Brus L, Winge D. Biosynthesis of cadmium sulphide quantum semiconductor crystallites. Nature. 1989;338:596-7.

88. Kowshik M, Ashtaputre S, Kharrazi S, Vogel W, Urban J, Kulkarni SK, Paknikar KM. Extracellular synthesis of silver nanoparticles by a silver-tolerant yeast strain MKY3. Nanotechnology. 2003;14(1):95-100.

89. Narayanan KB, Sakthivel N. Biological synthesis of metal nanoparticles by microbes. Advances in Colloid and Interface Science. 2010;156(1-2):1-13.

90. Jha AK, Prasad K, Prasad K. A green low-cost biosynthesis of Sb2O3 nanoparticles. Biochemical Engineering Journal. 2009;43(3):303-6.

91. Agnihotri M, Joshi S, Kumar AR, Zinjarde S, Kulkarni S. Biosynthesis of gold nanoparticles by the tropical marine yeast Yarrowia lipolytica NCIM 3589. Materials Letters. 2009;63(15):1231-4.

92. Mirzadeh S, Darezereshki E, Bakhtiari F, Fazaelipoor MH, Hosseini MR. Characterization of zinc sulfide $(\mathrm{ZnS})$ nanoparticles Biosynthesized by Fusarium oxysporum. Materials Science in Semiconductor Processing. 2013;16(2):374-8.

93. Bansal V, Rautaray D, Bharde A, Ahire K, Sanyal A, Ahmad A, Sastry M. Fungusmediated biosynthesis of silica and titania particles. Journal of Materials Chemistry. 2005;15(26):2583-9.

94. Riddin TL, Gericke M, Whiteley CG. Analysis of the inter- and extracellular formation of platinum nanoparticles by Fusarium oxysporum f. sp. lycopersici using response surface methodology. Nanotechnology 2006;17(14):3482-9.

95. Al-Askar A, Hafez E, Kabeil S, Meghad A. Bioproduction of silver-nano particles by Fusarium oxysporum and their antimicrobial activity against some plant pathogenic bacteria and fungi. Life Science Journal. 2013;10(3):2470-6.

96. Gherbawy Y, Shalaby I, El-sadek M, Elhariry H, Banaja A: The Anti-Fasciolasis Properties of Silver Nanoparticles Produced by Trichoderma harzianum and Their 
Improvement of the Anti-Fasciolasis Drug Triclabendazole. International Journal of Molecular Sciences. 2013;14(11):21887-98.

97. Sanghi R, Verma P: Biomimetic synthesis and characterisation of protein capped silver nanoparticles. Bioresource Technology. 2009;100(1):501-4.

98. Duran N, Marcato PD, Duran M, Yadav A, Gade A, Rai M. Mechanistic aspects in the biogenic synthesis of extracellular metal nanoparticles by peptides, bacteria, fungi, and plants. Applied Microbiology and Biotechnology. 2011;90(5):1609-24.

99. Durán N, Marcato PD, Alves OL, De Souza GI, Esposito E. Mechanistic aspects of biosynthesis of silver nanoparticles by several Fusarium oxysporum strains. Journal of Nanobiotechnology. 2005;3(8):1-7.

100. Walker GM. Yeast Physiology and Biotechnology. New York: Wiley; 1998. 362p. 101. Lin L, Wu W, Huang J, Sun D, Waithera NuM, Zhou Y, Wang H, Li Q. Catalytic gold nanoparticles immobilized on yeast: From biosorption to bioreduction. Chemical Engineering Journal. 2013;225:857-64.

102. Breierova E, Vajczikova I, Sasinkova V, Stratilova E, Fisera I, Gregor T, Sajbidor J. Biosorption of cadmium ions by different yeast species. Zeitschrift für Naturforschung C. 2002;57(7-8):634-9.

103. Gade A, Ingle A, Whiteley C, Rai M. Mycogenic metal nanoparticles: progress and applications. Biotechnology Letters. 2010;32(5):593-600.

104. Krumov N, Perner-Nochta I, Oder S, Gotchev V, Angelov A, Posten C. Production of Inorganic Nanoparticles by Microorganisms. Chemical Engineering \& Technology. 2009;32(7):1026-35.

105. Kumari A, Kumar V, Yadav SK. Plant Extract Synthesized PLA Nanoparticles for Controlled and Sustained Release of Quercetin: A Green Approach. Plos One. 2012;7(7). 106. Akhtar MS, Panwar J, Yun Y-S. Biogenic Synthesis of Metallic Nanoparticles by Plant Extracts. ACS Sustainable Chemistry \& Engineering. 2013;1(6):591-602.

107. Kumar V, Yadav SK. Plant-mediated synthesis of silver and gold nanoparticles and their applications. Journal of Chemical Technology \& Biotechnology. 2009;84(2):151-7. 108. Gardea-Torresdey JL, Tiemann KJ, Parsons JG, Gamez G, Yacaman MJ. Characterization of trace level $\mathrm{Au}$ (III) binding to alfalfa biomass (Medicago sativa) by GFAAS. Advances in Environmental Research. 2002;6(3):313-23.

109. Chandran SP, Chaudhary M, Pasricha R, Ahmad A, Sastry M. Synthesis of gold nanotriangles and silver nanoparticles using Aloe vera plant extract. Biotechnology Progress. 2006;22(2):577-83.

110. Shukla R, Nune SK, Chanda N, Katti K, Mekapothula S, Kulkarni RR, Welshons WV, Kannan R, Katti KV. Soybeans as a phytochemical reservoir for the production and stabilization of biocompatible gold nanoparticles. Small. 2008;4(9):1425-36.

111. Nune SK, Chanda N, Shukla R, Katti K, Kulkarni RR, Thilakavathy S, Mekapothula S, Kannan R, Katti KV. Green nanotechnology from tea: phytochemicals in tea as 
building blocks for production of biocompatible gold nanoparticles. Journal of Materials Chemistry. 2009;19(19):2912-20.

112. Das J, Das MP, Velusamy P. Sesbania grandiflora leaf extract mediated green synthesis of antibacterial silver nanoparticles against selected human pathogens. Spectrochimica Acta Part A: Molecular and Biomolecular Spectroscopy. 2013;104:265-70.

113. Patil RS, Kokate MR, Kolekar SS. Bioinspired synthesis of highly stabilized silver nanoparticles using Ocimum tenuiflorum leaf extract and their antibacterial activity. Spectrochimica Acta Part A: Molecular and Biomolecular Spectroscopy. 2012;91:234-8. 114. Ahmad N, Sharma S, Alam MK, Singh VN, Shamsi SF, Mehta BR, Fatma A. Rapid synthesis of silver nanoparticles using dried medicinal plant of basil. Colloids and Surfaces B: Biointerfaces. 2010;81(1):81-6.

115. Maensiri S, Laokul P, Klinkaewnarong J, Phokha S, Promarak V, Seraphin S. Indium oxide (In2O3) nanoparticles using Aloe vera plant extract: Synthesis and optical properties. Journal of Optoelectronics and Advanced Materials. 2008;10(3):161-5.

116. Krishnaraj C, Jagan EG, Rajasekar S, Selvakumar P, Kalaichelvan PT, Mohan N. Synthesis of silver nanoparticles using Acalypha indica leaf extracts and its antibacterial activity against water borne pathogens. Colloids and Surfaces B: Biointerfaces. 2010;76(1):50-6.

117. Quelemes PV, Araruna FB, de Faria BEF, Kuckelhaus SAS, da Silva DA, Mendonca RZ, Eiras C, Soares MJdS, Leite JRSA. Development and Antibacterial Activity of Cashew Gum-Based Silver Nanoparticles. International Journal of Molecular Sciences. 2013;14(3):4969-81.

118. Shameli K, Bin Ahmad M, Jaffar Al-Mulla EA, Ibrahim NA, Shabanzadeh P, Rustaiyan A, Abdollahi Y, Bagheri S, Abdolmohammadi S, Usman MS, Zidan M. Green biosynthesis of silver nanoparticles using Callicarpa maingayi stem bark extraction. Molecules. 2012;17(7):8506-17.

119. Li S, Shen Y, Xie A, Yu X, Qiu L, Zhang L, Zhang Q. Green synthesis of silver nanoparticles using Capsicum annuum L. extract. Green Chemistry. 2007;9(8):852.

120. Yang X, Li Q, Wang H, Huang J, Lin L, Wang W, Sun D, Su Y, Opiyo JB, Hong L, Wang Y, He N, Jia L. Green synthesis of palladium nanoparticles using broth of Cinnamomum camphora leaf. Journal of Nanoparticle Research. 2009;12(5):1589-98.

121. Huang J, Li Q, Sun D, Lu Y, Su Y, Yang X, Wang H, Wang Y, Shao W, He N, Hong J, Chen C. Biosynthesis of silver and gold nanoparticles by novel sundried Cinnamomum camphora leaf. Nanotechnology. 2007;18(10):105104.

122. Smitha SL, Philip D, Gopchandran KG. Green synthesis of gold nanoparticles using Cinnamomum zeylanicum leaf broth. Spectrochimica Acta Part A: Molecular and Biomolecular Spectroscopy. 2009;74(3):735-9. 
123. Sathishkumar M, Sneha K, Won SW, Cho CW, Kim S, Yun YS. Cinnamon zeylanicum bark extract and powder mediated green synthesis of nano-crystalline silver particles and its bactericidal activity. Colloids and Surfaces B: Biointerfaces. 2009;73(2):332-8. 124. Babu PJ, Das RK, Kumar A, Bora U. Microwave-mediated synthesis of gold nanoparticles using coconut water. International Journal of Green Nanotechnology. 2011;3(1):13-21.

125. Narayanan KB, Sakthivel N. Coriander leaf mediated biosynthesis of gold nanoparticles. Materials Letters. 2008;62(30):4588-90.

126. Sneha K, Sathishkumar M, Lee SY, Bae MA, Yun Y-S. Biosynthesis of Au nanoparticles using cumin seed powder extract. Journal of Nanoscience and Nanotechnology. 2011;11(2):1811-4.

127. Song JY, Kwon EY, Kim BS. Biological synthesis of platinum nanoparticles using Diopyros kaki leaf extract. Bioprocess and Biosystems Engineering. 2010;33(1):159-64. 128. Jia L, Zhang Q, Li Q, Song H. The biosynthesis of palladium nanoparticles by antioxidants in Gardenia jasminoides Ellis: long lifetime nanocatalysts for p-nitrotoluene hydrogenation. Nanotechnology. 2009;20(38):385601.

129. Kumar PR. Soybean (Glycine max) Leaf Extract Based Green Synthesis of Palladium Nanoparticles. Journal of Biomaterials and Nanobiotechnology. 2012;03(01):14-9.

130. Liny P, Divya T, Malakar B, Nagaraj B, Krishnamurthy N, Dinesh R. Preparation of gold nanoparticles from Helianthus annuus (sun flower) flowers and evaluation of their antimicrobial activities. International Journal of Pharma \& Bio Sciences. 2012;3(1).

131. Lukman AI, Gong B, Marjo CE, Roessner U, Harris AT. Facile synthesis, stabilization, and anti-bacterial performance of discrete Ag nanoparticles using Medicago sativa seed exudates. Journal of Colloid and Interface Science. 2011;353(2):433-4.

132. MubarakAli D, Thajuddin N, Jeganathan K, Gunasekaran M. Plant extract mediated synthesis of silver and gold nanoparticles and its antibacterial activity against clinically isolated pathogens. Colloids and Surfaces B: Biointerfaces. 2011;85(2):360-5. 133. Das RK, Gogoi N, Bora U. Green synthesis of gold nanoparticles using Nyctanthes arbortristis flower extract. Bioprocess and Biosystems Engineering. 2011;34(5):615-9.

134. Vijayaraghavan K, Nalini S, Prakash NU, Madhankumar D. One step green synthesis of silver nano/microparticles using extracts of Trachyspermum ammi and Papaver somniferum. Colloids and Surfaces B: Biointerfaces. 2012;94:114-7.

135. Raja K, Saravanakumar A, Vijayakumar R. Efficient synthesis of silver nanoparticles from Prosopis juliflora leaf extract and its antimicrobial activity using sewage. Spectrochimica Acta Part A: Molecular and Biomolecular Spectroscopy. 2012;97:490-4. 136. Mittal AK, Kaler A, Banerjee UC. Free radical scavenging and antioxidant activity of silver nanoparticles synthesized from flower extract of Rhododendron dauricum. Nano Biomedicine and Engineering. 2012;4(3):118-24. 
137. Dubey SP, Lahtinen M, Sarkka H, Sillanpaa M. Bioprospective of Sorbus aucuparia leaf extract in development of silver and gold nanocolloids. Colloids and Surfaces B: Biointerfaces. 2010;80(1):26-33.

138. Ankamwar B, Chaudhary M, Sastry M. Gold nanotriangles biologically synthesized using tamarind leaf extract and potential application in vapor sensing. Synthesis and Reactivity in Inorganic, Metal-Organic and Nano-Metal Chemistry. 2005;35(1):19-26. 139. Ajitha B, Ashok Kumar Reddy Y, Reddy PS. Biogenic nano-scale silver particles by Tephrosia purpurea leaf extract and their inborn antimicrobial activity. Spectrochimica Acta Part A: Molecular and Biomolecular Spectroscopy. 2013;121C:164-72.

140. Song JY, Kim BS. Rapid biological synthesis of silver nanoparticles using plant leaf extracts. Bioprocess and Biosystems Engineering. 2009;32(1):79-84.

141. Velayutham K, Rahuman AA, Rajakumar G, Roopan SM, Elango G, Kamaraj C, Marimuthu S, Santhoshkumar T, Iyappan M, Siva C. Larvicidal activity of green synthesized silver nanoparticles using bark aqueous extract of Ficus racemosa against Culex quinquefasciatus and Culex gelidus. Asian Pacific Journal of Tropical Medicine. 2013;6(2):95-101.

142. Gnanadesigan M, Anand M, Ravikumar S, Maruthupandy M, Ali MS, Vijayakumar V, Kumaraguru A. Antibacterial potential of biosynthesised silver nanoparticles using Avicennia marina mangrove plant. Applied Nanoscience. 2012;2(2):143-7.

143. Savithramma N, Rao ML, Rukmini K, Suvarnalatha P. Antimicrobial activity of silver nanoparticles synthesized by using medicinal plants. International Journal of ChemTech Research. 2011;3(3):1394-402.

144. Anshup, Venkataraman JS, Subramaniam C, Kumar RR, Priya S, Kumar TRS, Omkumar RV, John A, Pradeep T. Growth of gold nanoparticles in human cells. Langmuir. 2005;21(25):11562-7.

145. Douglas T, Strable E, Willits D, Aitouchen A, Libera M, Young M. Protein engineering of a viral cage for constrained nanomaterials synthesis. Advanced Materials. 2002;14(6):415-+.

146. Shenton W, Douglas T, Young M, Stubbs G, Mann S. Inorganic-organic nanotube composites from template mineralization of tobacco mosaic virus. Advanced Materials. 1999;11(3):253-+.

147. Lee SW, Mao CB, Flynn CE, Belcher AM. Ordering of quantum dots using genetically engineered viruses. Science. 2002;296(5569):892-5.

148. Ramezani F, Jebali A, Kazemi B. A Green Approach for Synthesis of Gold and Silver Nanoparticles by Leishmania sp. Applied Biochemistry and Biotechnology. 2012;168(6):1549-55.

149. Jain N, Bhargava A, Tarafdar JC, Singh SK, Panwar J. A biomimetic approach towards synthesis of zinc oxide nanoparticles. Applied Microbiology and Biotechnology. 2013;97(2):859-69. 
150. Iravani S. Green synthesis of metal nanoparticles using plants. Green Chemistry. 2011;13(10):2638.

151. Ingale AG, Chaudhari AN. Biogenic Synthesis of Nanoparticles and Potential Applications: An Eco- Friendly Approach. Journal of Nanomedicine \& Nanotechnology. 2013;04(02).

152. Krishnaraj C, Ramachandran R, Mohan K, Kalaichelvan PT. Optimization for rapid synthesis of silver nanoparticles and its effect on phytopathogenic fungi. Spectrochimica Acta Part A: Molecular and Biomolecular Spectroscopy. 2012;93:95-9.

153. Prabakar K, Sivalingam P, Rabeek SIM, Muthuselvam M, Devarajan N, Arjunan A, Karthick R, Suresh MM, Wembonyama JP. Evaluation of antibacterial efficacy of phyto fabricated silver nanoparticles using Mukia scabrella (Musumusukkai) against drug resistance nosocomial gram negative bacterial pathogens. Colloids and Surfaces B: Biointerfaces. 2013;104:282-8.

154. Santhoshkumar T, Rahuman AA, Rajakumar G, Marimuthu S, Bagavan A, Jayaseelan C, Zahir AA, Elango G, Kamaraj C. Synthesis of silver nanoparticles using Nelumbo nucifera leaf extract and its larvicidal activity against malaria and filariasis vectors. Parasitology Research. 2011;108(3):693-702.

155. Suganya A, Murugan K, Kovendan K, Kumar PM, Hwang J-S. Green synthesis of silver nanoparticles using Murraya koenigii leaf extract against Anopheles stephensi and Aedes aegypti. Parasitology Research. 2013;112(4):1385-97.

156. Raghunandan D, Ravishankar B, Sharanbasava G, Mahesh DB, Harsoor V, Yalagatti MS, Bhagawanraju M, Venkataraman A. Anti-cancer studies of noble metal nanoparticles synthesized using different plant extracts. Cancer Nanotechnology. 2011;2(1-6):57-65. 157. Prasad T, Elumalai E. Biofabrication of Ag nanoparticles using Moringa oleifera leaf extract and their antimicrobial activity. Asian Pacific Journal of Tropical Biomedicine. 2011;1(6):439-42.

158. Subramanian V, Suja S. Green synthesis of silver nanoparticles using Coleus amboinicus lour, antioxitant activity and invitro cytotoxicity against Ehrlich's Ascite carcinoma. Journal of Pharmacy Research. 2012;5(2).

159. Chen X-J, Sanchez-Gaytan BL, Qian Z, Park S-J. Noble metal nanoparticles in DNA detection and delivery. Wiley Interdisciplinary Reviews-Nanomedicine and Nanobiotechnology. 2012;4(3):273-90.

160. Doria G, Conde J, Veigas B, Giestas L, Almeida C, Assunção M, Rosa J, Baptista PV. Noble metal nanoparticles for biosensing applications. Sensors. 2012;12(2):1657-87. 161. Youns M, Hoheisel JD, Efferth T. Therapeutic and Diagnostic Applications of Nanoparticles. Current Drug Targets. 2011;12(3):357-65. 
